\title{
Comparison of Transport Properties Models for Flowfield Simulations of Ablative Heat Shields
}

\author{
Hicham Alkandry* and Iain D. Boyd \\ University of Michigan, Ann Arbor, Michigan 48109 \\ and \\ Alexandre Martin \\ University of Kentucky, Lexington, Kentucky 40506 \\ DOI: $\underline{10.2514 / 1 . T 4233}$
}

\begin{abstract}
The goal of this study is to evaluate the effects of different models for calculating the mixture transport properties on flowfield predictions of ablative heat shields. The Stardust sample return capsule at four different trajectory conditions is used as a representative environment for Earth entry. In the first part of the study, the results predicted using Wilke's missing rule, with species viscosities calculated using Blottner's curve fits and species thermal conductivities determined using Eucken's relation, are compared to the results obtained using Gupta's mixing rule with collision cross-section data. The heat transfer to the vehicle predicted using the Wilke/Blottner/Eucken model is found to be larger than the value obtained using the Gupta/collision cross-section model by as much as $60 \%$. The Wilke/Blottner/Eucken model also produces a larger mass blowing rate due to the oxidation of bulk carbon by as much as $\mathbf{2 5 \%}$ compared to the Gupta/collision cross-section model. In the second part of the study, the effects of the mass diffusion model are assessed using the Fick's, modified Fick's, self-consistent effective binary diffusion, and Stefan-Maxwell models. The results show that the flowfield properties calculated using the modified Fick's, self-consistent effective binary diffusion, and Stefan-Maxwell models are in good agreement. However, the Fick's model produces a larger heat transfer and mass blowing rate compared to the other diffusion models by as much as $20 \%$.
\end{abstract}

\section{Nomenclature}

$C_{p}=$ specific heat at constant pressure, $\mathrm{J} / \mathrm{K} / \mathrm{kg}$

$C_{v}=$ specific heat at constant volume, $\mathrm{J} / \mathrm{K} / \mathrm{kg}$

$D_{s}=$ diffusion coefficient of species $s, \mathrm{~m}^{2} / \mathrm{s}$

$D_{s, r}=$ binary diffusion coefficient of species $s$ and $r, \mathrm{~m}^{2} / \mathrm{s}$

$\boldsymbol{J}_{s}=$ mass diffusion flux of species $s, \mathrm{~kg} / \mathrm{m}^{2} / \mathrm{s}$

$k_{B}=$ Boltzmann constant, $1.38 \times 10^{-23} \mathrm{~kg} \cdot \mathrm{m}^{2} / \mathrm{s}^{2} / \mathrm{K}$

$M=$ average molar weight of the gas-phase mixture, $\mathrm{kg} / \mathrm{mol}$

$M_{s} \quad=$ molar weight of species $s, \mathrm{~kg} / \mathrm{mol}$

$m_{s} \quad=$ mass of species $s, \mathrm{~kg}$

$N S=$ number of gas-phase species

$N_{\text {av }}=$ Avogadro's number, $6.022 \times 10^{23} \mathrm{~mol}^{-1}$

$p=$ pressure, $\mathrm{Pa}$

$p_{s}=$ partial pressure of species $s, \mathrm{~Pa}$

$R=$ universal gas constant, $8.314 \mathrm{~J} / \mathrm{mol} / \mathrm{K}$

$T_{\mathrm{tr}}=$ translational/rotational temperature, $\mathrm{K}$

$T_{\mathrm{ve}}=$ vibrational/electronic/electron temperature, $\mathrm{K}$

$X_{s} \quad=$ mole fraction of species $s$

$Y_{s} \quad=$ mass fraction of species $s$

$\gamma_{s}=$ molar concentration of species $s, \mathrm{~mol} / \mathrm{kg}$

$\Delta_{s, r}=$ collision terms between species $s$ and $r, \mathrm{~m} \cdot \mathrm{s}$

$\kappa=$ coefficient of thermal conductivity of the gas-phase mixture, $\mathrm{W} / \mathrm{m} / \mathrm{K}$
Presented as Paper 2013-0303 at the 51st AIAA Aerospace Sciences Meeting Including the New Horizons Forum and Aerospace Exposition, Grapevine (Dallas/Ft. Worth Region), TX, 7-10 January 2013; received 16 July 2013; revision received 21 April 2014; accepted for publication 19 May 2014; published online 28 August 2014. Copyright $\odot 2014$ by H. Alkandry, I. D. Boyd, and A. Martin. Published by the American Institute of Aeronautics and Astronautics, Inc., with permission. Copies of this paper may be made for personal or internal use, on condition that the copier pay the $\$ 10.00$ per-copy fee to the Copyright Clearance Center, Inc., 222 Rosewood Drive, Danvers, MA 01923; include the code 1533-6808/14 and \$10.00 in correspondence with the CCC.

*Research Fellow, Department of Aerospace Engineering. Member AIAA.

$\dagger$ James E. Knott Professor of Engineering, Department of Aerospace Engineering. Fellow AIAA.

${ }^{*}$ Assistant Professor, Department of Mechanical Engineering. Senior Member AIAA.

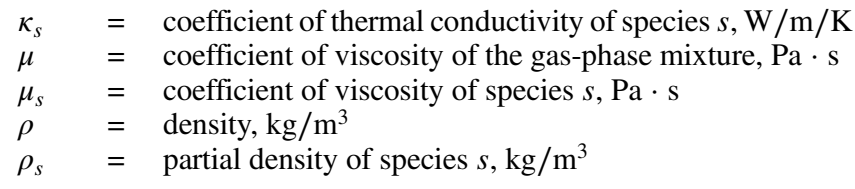

\section{Introduction}

$\mathbf{M}$ ANY planetary entry vehicles employ an ablative thermal protection system (TPS) in order to sustain the very large heat fluxes experienced during atmospheric entry. The hypersonic flow around these entry vehicles interacts with the TPS, which may cause some ablation byproducts to be transported across the boundary layer into the flowfield. Several models exist to simulate these transport phenomena using computational fluid dynamics (CFD). These models, however, may give different transport rates, which can have a significant effect on the predicted aerothermal properties of the entry vehicle. Therefore, the goal of this study is to assess the effects of transport models on CFD predictions of hypersonic flow around ablative heat shields. Several other studies have investigated the effects of the mixture transport models on the predicted flowfield and surface properties of planetary entry vehicles [1 $\underline{-}$ ] . These studies have shown that the mixture transport model can have an important effect on the predicted flowfield and heat transfer to the entry vehicles. However, these studies have mainly focused on catalytic nonablative TPS materials. The current study aims to extend the analysis to ablative heat shields and consider models for both the mixture transport coefficients (i.e., viscosity, thermal conductivity, and mass diffusion) and mass diffusion fluxes.

For this study, CFD simulations are performed using the reentry conditions for the Stardust sample return capsule. In the first part of the study, the effects of two different models for calculating the mixture transport coefficients are investigated. The first model considered is Wilke's semiempirical mixing rule, with species viscosities and thermal conductivities determined using Blottner's curve fits and Eucken's relation, respectively. The second model is Gupta's mixing rule using collision cross-section data to determine the viscosity and thermal conductivity of individual species. A modified form of the Fick's model is used to calculate the mass 
diffusion fluxes for both sets of simulations. The effects of the mass diffusion model are assessed in the second part of the study using the Fick's model, the modified Fick's model, the self-consistent effective binary diffusion (SCEBD) model, and the Stefan-Maxwell model. Gupta's mixing rule with collision cross-section data is used to calculate the mixture transport coefficients. The paper is presented as follows. First, the CFD code and formulation of the different models used in this study are described. Then, details about the Stardust sample return capsule and numerical setup are provided. Finally, the numerical results obtained using these different transport models are presented and discussed.

\section{Governing Equations}

The numerical simulations are performed using the CFD code LeMANS, which was developed at the University of Michigan [6,7]. LeMANS solves the laminar Navier-Stokes equations on unstructured computational grids, including thermochemical nonequilibrium effects with second-order spatial accuracy. In LeMANS, the flow is modeled assuming that the continuum approximation is valid. Furthermore, for this study, it is assumed that the translational and rotational energy modes can be described by a single temperature $T_{\mathrm{tr}}$; and the vibrational, electronic, and electron translational energy modes are described by a different temperature $T_{\text {ve }}$. The finite volume method is used to solve the set of partial differential equations. A modified Steger-Warming flux vector splitting scheme is used to discretize the inviscid fluxes across cell faces, which is less dissipative and produces better results in boundary layers compared to the original scheme [8]. The viscous terms are computed using cell-centered and nodal values. The viscous stresses are modeled assuming a Newtonian fluid and Stokes' hypothesis, and the heat fluxes are modeled according to Fourier's law for each temperature. A finite-rate surface chemistry module originally developed by Marschall and MacLean [9] and MacLean et al. [10] has been implemented in LeMANS as a boundary condition to model the interaction between the hypersonic gas flow and the vehicle surface [11]. This module allows for the specification of several different surface reaction processes, including adsorption/ desorption, Eley-Rideal recombination, and oxidation/nitridation. The module calculates the species production rates at the surface based on the pressure, temperature, and species concentrations at the wall. The effects of pyrolysis gases emitted from the surface are neglected in this study, and the only contribution to the mass blowing rate is due to the removal of bulk species by surface reactions such as oxidation. LeMANS is parallelized using METIS [12] to partition the computational mesh, and the message-passing interface is used to communicate the necessary information between processors.

\section{A. Mixture Transport Coefficients}

Two models are considered in this study for computing the mixture transport coefficients in the CFD simulations. The first model considered is Wilke's semiempirical mixing rule, with species viscosities and thermal conductivities determined using Blottner's curve fits and Eucken's relation, respectively. The second model is Gupta's mixing rule using collision cross-section data to determine the viscosity and thermal conductivity of individual species. The mass diffusion fluxes are calculated using a modified form of the Fick's model for both sets of cases.

\section{Wilke/Blottner/Eucken}

The Wilke/Blottner/Eucken model is the first model considered for calculating the mixture transport coefficients. This model employs Wilke's mixing rule [13], which is a simplification of the ChapmanEnskog relation, along with curve fits determined by Blottner et al. [14] for the species viscosities, and it employs Eucken's relation [15] for the species thermal conductivities. Wilke's mixing rule [13] has been shown to produce adequate results for relatively slow Earth entry speeds, for which the maximum temperature in the flowfield is around $10,000 \mathrm{~K}[\underline{4}, \underline{5}]$. Using this model, the mixture viscosity and thermal conductivity for each energy mode can be calculated as an appropriately weighted sum of the individual species viscosities and thermal conductivities by

$$
\mu=\sum_{s} \frac{X_{s} \mu_{s}}{\phi_{s}} \quad \text { and } \quad \kappa=\sum_{s} \frac{X_{s} \kappa_{s}}{\phi_{s}}
$$

where the scaling factor $\phi_{s}$ is given by

$$
\phi_{s}=\sum_{r} X_{r}\left[1+\sqrt{\frac{\mu_{s}}{\mu_{r}}}\left(\frac{M_{r}}{M_{s}}\right)^{1 / 4}\right]^{2}\left[\sqrt{8\left(1+\frac{M_{s}}{M_{r}}\right)}\right]^{-1}
$$

The coefficient of the viscosity of each species is calculated using Blottner's curve fits [14] as

$$
\mu_{s}=0.1 \exp \left[\left(A_{s} \ln T_{\mathrm{tr}}+B_{s}\right) \ln T_{\mathrm{tr}}+C_{s}\right]
$$

where $A, B$, and $C$ are constants determined for each species.

The coefficient of thermal conductivity for the different energy modes can be calculated using Eucken's relation [15]:

$$
\kappa_{\mathrm{tr}, s}=\frac{5}{2} \mu_{s} C_{v_{t, s}}+\mu_{s} C_{v_{r, s}} \quad \kappa_{\mathrm{ve}, s}=\mu_{s} C_{v_{\mathrm{ve}, s}}
$$

where $C_{v_{t, r, v e}}$ are the specific heats at constant volume for each internal energy mode.

The effective, or average, diffusion coefficient for each species is replaced by a single coefficient calculated using the mixture coefficient of thermal conductivity and given by

$$
D_{s}=D=\frac{\kappa_{\mathrm{tr}} L e}{\rho C_{p_{\mathrm{tr}}}}
$$

where $C_{p_{\text {tr }}}$ is the mixture translational/rotational specific heat at constant pressure, and $L e$ is the Lewis number that is assumed to be constant. For this study, the Lewis number is assumed to be equal to 1.4 .

\section{Gupta/Collision Cross-Section Data}

Gupta et al. [16] developed another model for calculating the mixture transport properties for weakly ionized flows. This model is considered to be more physically accurate than the Wilke/Blottner/ Eucken model because it takes into account the collision integrals in the multicomponent mixture [4]. These collision integrals are evaluated at a controlling temperature for each collision pair. For collisions between two heavy particles, the controlling temperature is chosen as the translational/rotational temperature $T_{\mathrm{tr}}$. The vibrational/electron/electronic temperature $T_{\mathrm{ve}}$ is used as the controlling temperature for collisions involving electrons. Gupta's mixing rule has also been shown to be more numerically efficient than Wilke's mixing rule [13] because it requires fewer calls to the power (exponent) and square-root functions [4] ] Using Gupta's mixing rule, the mixture viscosity can be calculated by

$$
\mu=\sum_{s \neq e} \frac{m_{s} \gamma_{s}}{\sum_{r \neq e} \gamma_{r} \Delta_{s, r}^{(2)}\left(T_{\mathrm{tr}}\right)+\gamma_{e} \Delta_{s, e}^{(2)}\left(T_{\mathrm{ve}}\right)}+\frac{m_{e} \gamma_{e}}{\sum_{r} \gamma_{r} \Delta_{e, r}^{(2)}\left(T_{\mathrm{ve}}\right)}
$$

where the collision terms $\Delta_{s, r}$ are evaluated at the different controlling temperatures $T_{\mathrm{tr}}$ and $T_{\mathrm{ve}}$. The molar concentration of each species, $\gamma_{s}$, can be calculated by

$$
\gamma_{s}=\frac{\rho_{s}}{\rho M_{s}}
$$

The mass of each species, $m_{s}$, is given by 


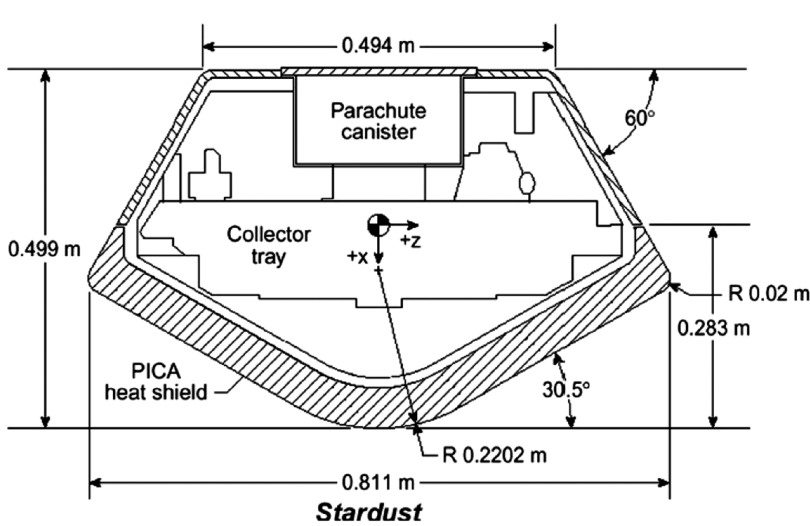

a) Geometry

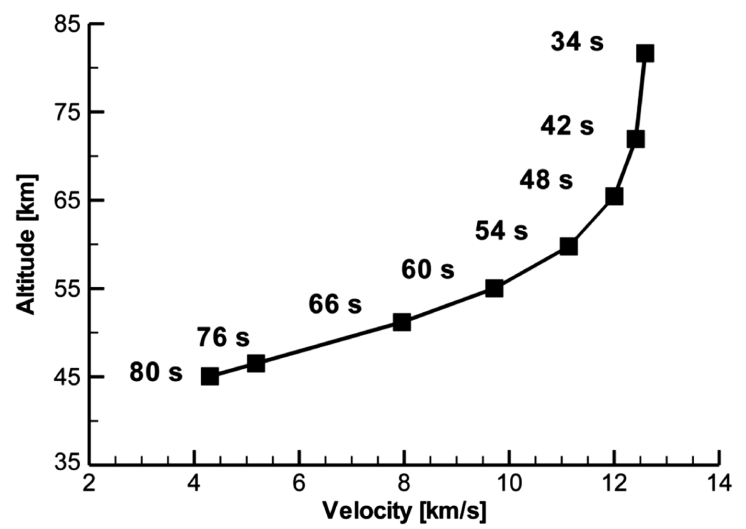

b) Trajectory

Fig. 1 Stardust sample return capsule geometry and entry trajectory.

$$
m_{s}=\frac{M_{s}}{N_{\mathrm{av}}}
$$

The mixture thermal conductivity for the translational mode can be calculated by

$$
\kappa_{t}=\frac{15}{4} k_{B} \sum_{s \neq e} \frac{\gamma_{s}}{\sum_{r \neq e} a_{s, r} \gamma_{r} \Delta_{s, r}^{(2)}\left(T_{\mathrm{tr}}\right)+3.54 \gamma_{e} \Delta_{s, e}^{(2)}\left(T_{\mathrm{ve}}\right)}
$$

where

$$
a_{s, r}=1+\frac{\left[1-\left(m_{s} / m_{r}\right)\right]\left[0.45-2.54\left(m_{s} / m_{r}\right)\right]}{\left[1+\left(m_{s} / m_{r}\right)\right]^{2}}
$$

The thermal conductivity for the rotational mode is given by

$$
\kappa_{r}=k_{B} \sum_{s=\mathrm{mol}} \frac{\gamma_{s}}{\sum_{r \neq e} \gamma_{r} \Delta_{s, r}^{(1)}\left(T_{\mathrm{tr}}\right)+\gamma_{e} \Delta_{s, e}^{(1)}\left(T_{\mathrm{ve}}\right)}
$$

where the summation $s$ is over all the molecules. The mixture thermal conductivity for the translational/rotational mode is equal to the sum of the conductivities for the translational [Eq. (9)] and the rotational [Eq. (11)] modes:

$$
\kappa_{\mathrm{tr}}=\kappa_{t}+\kappa_{r}
$$

The thermal conductivity for the vibrational/electronic mode can be calculated by

$$
\kappa_{\mathrm{vel}}=k_{B} \frac{C_{v_{\mathrm{ve}}}}{R} \sum_{s=\mathrm{mol}} \frac{\gamma_{s}}{\sum_{r \neq e} \gamma_{r} \Delta_{s, r}^{(1)}\left(T_{\mathrm{tr}}\right)+\gamma_{e} \Delta_{s, e}^{(1)}\left(T_{\mathrm{ve}}\right)}
$$

The thermal conductivity for electrons is given by

$$
\kappa_{e}=\frac{15}{4} k_{B} \frac{\gamma_{e}}{\sum_{r} 1.45 \gamma_{r} \Delta_{e, r}^{(2)}\left(T_{\mathrm{ve}}\right)}
$$

The collision terms, $\Delta_{s, r}^{(1)}$ and $\Delta_{s, r}^{(2)}$, can be calculated by

$$
\begin{aligned}
& \Delta_{s, r}^{(1)}=\frac{8}{3}\left[\frac{2 M_{s} M_{r}}{\pi R T\left(M_{s}+M_{r}\right)}\right]^{1 / 2} \pi \bar{\Omega}_{s, r}^{(1,1)} \\
& \Delta_{s, r}^{(2)}=\frac{16}{5}\left[\frac{2 M_{s} M_{r}}{\pi R T\left(M_{s}+M_{r}\right)}\right]^{1 / 2} \pi \bar{\Omega}_{s, r}^{(2,2)}
\end{aligned}
$$

where the collision integrals $\pi \bar{\Omega}_{s, r}^{(1,1)}$ and $\pi \bar{\Omega}_{s, r}^{(2,2)}$ can be determined using several different methods that usually rely on modeling the interaction potential for a pair of particles and integrating the differential cross section obtained from that potential over the entire solid angle space [16-18].

Table 2 Blottner's curve fit coefficients

\begin{tabular}{lrrr}
\hline \hline Species & \multicolumn{1}{c}{$\mathrm{A}$} & \multicolumn{1}{c}{$\mathrm{B}$} & $\mathrm{C}$ \\
\hline $\mathrm{N}_{2}$ & $2.68 \mathrm{E}-02$ & $3.18 \mathrm{E}-01$ & $-1.13 \mathrm{E}+01$ \\
$\mathrm{O}_{2}$ & $4.49 \mathrm{E}-02$ & $-8.26 \mathrm{E}-02$ & $-9.20 \mathrm{E}+00$ \\
$\mathrm{NO}$ & $4.36 \mathrm{E}-02$ & $-3.36 \mathrm{E}-02$ & $-9.58 \mathrm{E}+00$ \\
$\mathrm{~N}$ & $1.16 \mathrm{E}-02$ & $6.03 \mathrm{E}-01$ & $-1.24 \mathrm{E}+01$ \\
$\mathrm{O}$ & $2.03 \mathrm{E}-02$ & $4.29 \mathrm{E}-01$ & $-1.16 \mathrm{E}+01$ \\
$\mathrm{~N}_{2}^{+}$ & $2.68 \mathrm{E}-02$ & $3.18 \mathrm{E}-01$ & $-1.13 \mathrm{E}+01$ \\
$\mathrm{O}_{2}^{+}$ & $4.49 \mathrm{E}-02$ & $-8.26 \mathrm{E}-02$ & $-9.20 \mathrm{E}+00$ \\
$\mathrm{NO}^{+}$ & $3.02 \mathrm{E}-01$ & $-3.50 \mathrm{E}+00$ & $-3.74 \mathrm{E}+00$ \\
$\mathrm{~N}^{+}$ & $1.16 \mathrm{E}-02$ & $6.03 \mathrm{E}-01$ & $-1.24 \mathrm{E}+01$ \\
$\mathrm{O}^{+}$ & $2.03 \mathrm{E}-02$ & $4.29 \mathrm{E}-01$ & $-1.16 \mathrm{E}+01$ \\
$\mathrm{C}$ & $-1.00 \mathrm{E}-04$ & $7.93 \mathrm{E}-01$ & $-1.34 \mathrm{E}+01$ \\
$\mathrm{C}_{2}$ & $-3.10 \mathrm{E}-03$ & $6.92 \mathrm{E}-01$ & $-1.26 \mathrm{E}+01$ \\
$\mathrm{C}_{3}$ & $-1.47 \mathrm{E}-02$ & $8.81 \mathrm{E}-01$ & $-1.35 \mathrm{E}+01$ \\
$\mathrm{CO}$ & $-1.95 \mathrm{E}-02$ & $1.01 \mathrm{E}+00$ & $-1.40 \mathrm{E}+01$ \\
$\mathrm{CO}_{2}$ & $-1.95 \mathrm{E}-02$ & $1.05 \mathrm{E}+00$ & $-1.43 \mathrm{E}+01$ \\
$\mathrm{CN}^{+}$ & $2.50 \mathrm{E}-03$ & $6.81 \mathrm{E}-01$ & $-1.25 \mathrm{E}+01$ \\
$\mathrm{CO}^{+}$ & $-1.95 \mathrm{E}-02$ & $1.01 \mathrm{E}+00$ & $-1.40 \mathrm{E}+01$ \\
$\mathrm{C}^{+}$ & $-8.33 \mathrm{E}-03$ & $7.70 \mathrm{E}-01$ & $-1.27 \mathrm{E}+01$ \\
$\mathrm{e}$ & 0 & 0 & $-1.20 \mathrm{E}+01$ \\
\hline \hline
\end{tabular}

Table 1 Freestream conditions of the Stardust SRC used for this study

\begin{tabular}{lcccc}
\hline \hline Time from entry, & Altitude, $\mathrm{km}$ & Velocity, $\mathrm{m} / \mathrm{s}$ & Density, kg/m & Temperature, K \\
\hline 42 & 71 & 12,060 & $5.6 \times 10^{-5}$ & 222 \\
51 & 62 & 10,870 & $2.1 \times 10^{-4}$ & 235 \\
61 & 54 & 8,070 & $5.9 \times 10^{-4}$ & 251 \\
66 & 51 & 6,500 & $8.5 \times 10^{-4}$ & 256 \\
\hline \hline
\end{tabular}


Table 3 Surface chemical reactions $[27,28]$

\begin{tabular}{lcc}
\hline \hline No. & Reaction & Efficiency \\
\hline 1 & $\mathrm{O}+\mathrm{C}(b) \rightarrow \mathrm{CO}, \Delta H=360 \mathrm{~kJ} / \mathrm{mol}$ & 0.90 \\
2 & $\mathrm{O}_{2}+2 \mathrm{C}(b) \rightarrow 2 \mathrm{CO}, \Delta H=217 \mathrm{~kJ} / \mathrm{mol}$ & 0.01 \\
3 & $\mathrm{~N}+\mathrm{N} \rightarrow \mathrm{N}_{2}, \Delta H=950 \mathrm{~kJ} / \mathrm{mol}$ & 0.05 \\
\hline \hline
\end{tabular}

The binary diffusion coefficient involving two heavy particles is given by

$$
D_{s, r}=\frac{k_{B} T_{\mathrm{tr}}}{p \Delta_{s, r}^{(1)}\left(T_{\mathrm{tr}}\right)}
$$

and for electrons is given as

$$
D_{e, r}=\frac{k_{B} T_{\mathrm{ve}}}{p \Delta_{e, r}^{(1)}\left(T_{\mathrm{ve}}\right)}
$$

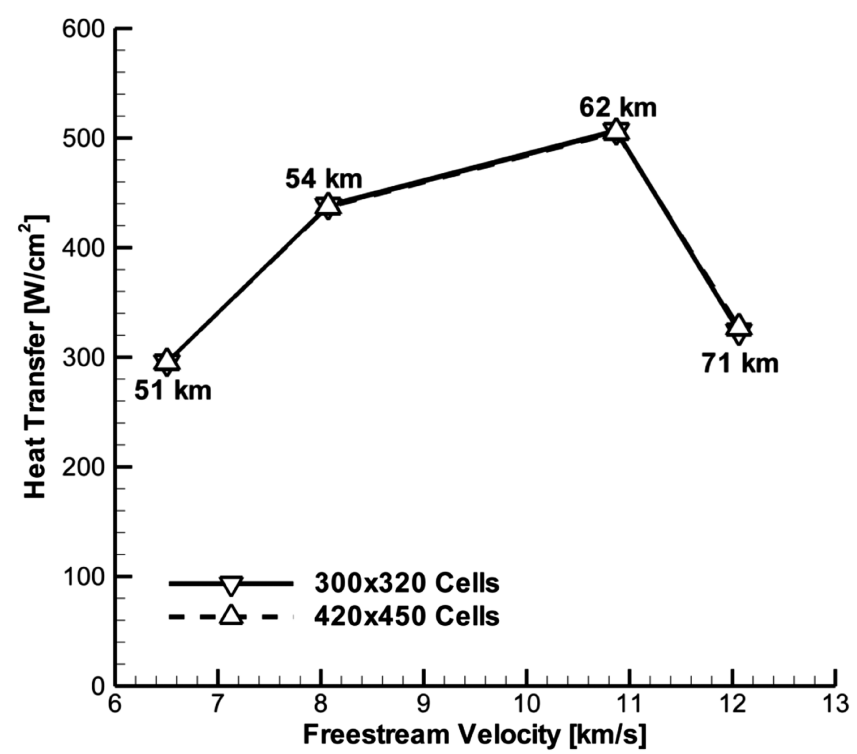

Fig. 2 Stagnation point heat transfer calculated using two different grid resolutions.
An effective diffusion coefficient can be defined by regarding the multicomponent mixture as a binary mixture made up of species $s$ and a composite species that represents all of the other species. This effective diffusion coefficient for species $s$ is calculated by [2]

$$
D_{s}=\left(1-X_{s}\right)\left(\sum_{r \neq s, e} \frac{X_{r}}{D_{s, r}}\right)^{-1}
$$

Note that the electrons are neglected in the summation because the electron diffusion flux is calculated assuming ambipolar diffusion to ensure that the flow is charge neutral.

\section{B. Mass Diffusion}

Four models for computing the mass diffusion fluxes in the CFD simulations are considered in this study. These models are the Fick's model, the modified Fick's model, the self-consistent effective binary diffusion model, and the Stefan-Maxwell model. The mixture transport coefficients are computed using the Gupta/collision crosssection (CCS) model.

\section{Fick's Model}

In a binary system with two chemical species $s$ and $r$, the Fick's law of diffusion states that each species moves relative to the mixture in the direction of decreasing mole fraction [19]. In terms of mass diffusion flux, the Fick's law can be written as

$$
J_{s}=-\rho D_{s, r} \nabla Y_{s}
$$

The Fick's law can be extended to a mixture of three or more species by replacing the binary diffusion coefficient $D_{s, r}$ by the effective diffusion coefficient $D_{s}$. The mass diffusion fluxes for heavy species are calculated in the Fick's model (extension of the Fick's law to multispecies mixtures) as

$$
\boldsymbol{J}_{s \neq e}=-\rho D_{s} \nabla Y_{s}
$$

The electron mass diffusion flux is calculated assuming ambipolar diffusion to ensure charge neutrality of the flow. It is given by

$$
\boldsymbol{J}_{e}=-\frac{1}{q_{e}} \sum_{s \neq e} q_{s} \boldsymbol{J}_{s}
$$

where $q_{s}$ is the charge per unit mass of species $s$.

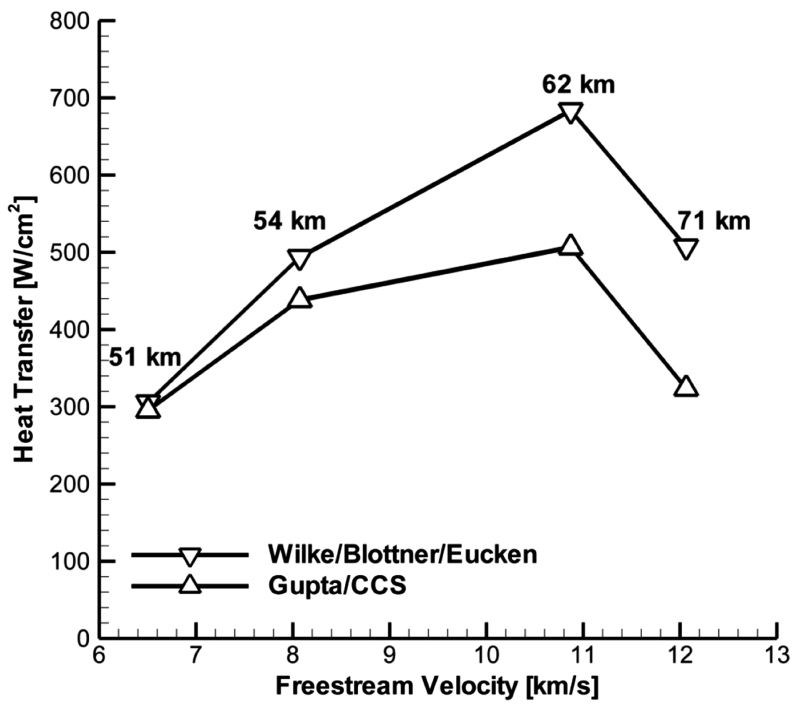

a) Finite-rate surface chemistry

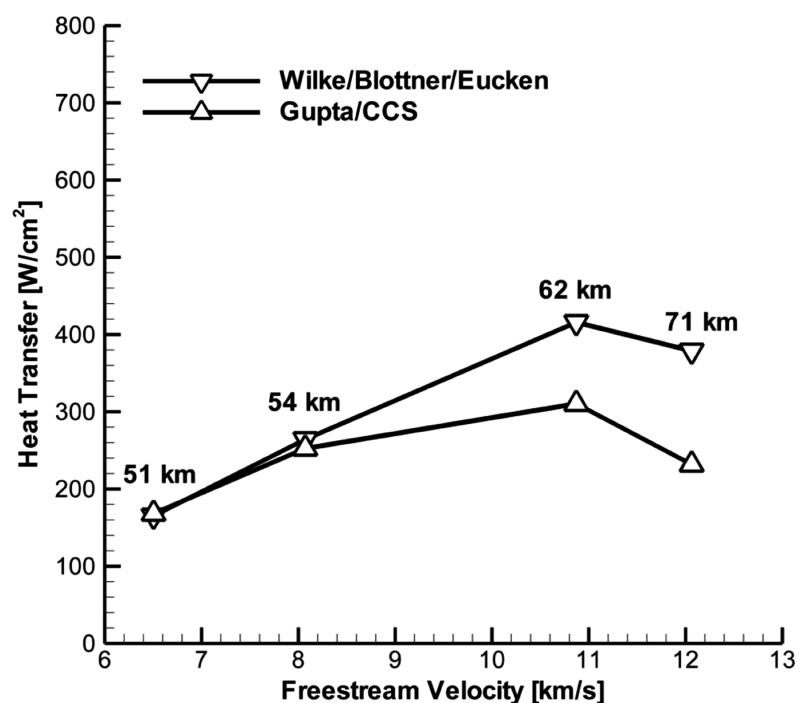

b) Noncatalytic wall

Fig. 3 Stagnation point heat transfer calculated using the Wilke/Blottner/Eucken and Gupta/CCS models. 


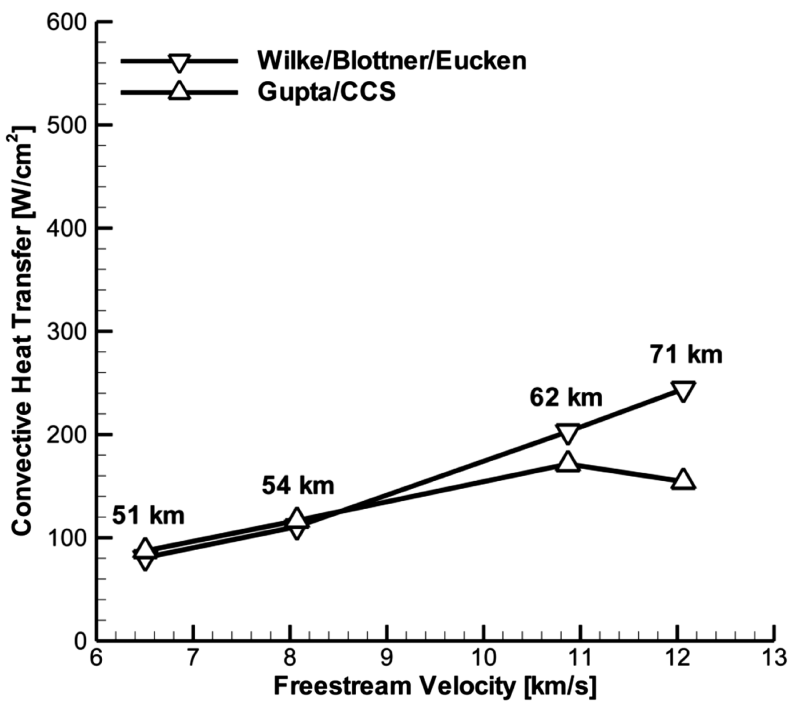

a) Convective

\section{Modified Fick's Model}

The Fick's model as defined in Eq. (21) does not enforce the requirement that the diffusion mass fluxes sum to zero [1]. Therefore, a modified version of the Fick's model is also considered in this study that ensures that the sum of the mass diffusion fluxes is zero. The diffusion flux for heavy species using the modified Fick's model can be calculated by

$$
J_{s \neq e}=-\rho D_{s} \nabla Y_{s}-Y_{s} \sum_{r \neq e}-\rho D_{r} \nabla Y_{r}
$$

The electron diffusion flux is calculated using Eq. (22) assuming ambipolar diffusion to enforce charge neutrality.

\section{Self-Consistent Effective Binary Diffusion Model}

Another model considered in this study is the self-consistent effective binary diffusion method, which was originally developed for computational simulations of multicomponent plasma flows $[20,21]$. The SCEBD model makes use of the small electron mass approximation to simplify the mass diffusion flux equations and the calculation of the electronic field in weakly ionized flows. The heavy species mass diffusion fluxes are determined by

$$
\begin{aligned}
\boldsymbol{J}_{s \neq e}= & -\frac{p M_{s} D_{s}}{R T_{\mathrm{tr}}} \nabla\left(\frac{p_{s}}{p}\right)+Y_{s} \sum_{r \neq e} \frac{p M_{r} D_{r}}{R T_{\mathrm{tr}}} \nabla\left(\frac{p_{r}}{p}\right) \\
& +\frac{1}{R T_{\mathrm{tr}}}\left[M_{s} q_{s} \rho_{s} D_{s}-Y_{s} \sum_{r \neq e} M_{r} q_{r} \rho_{r} D_{r}\right] \boldsymbol{E}
\end{aligned}
$$

where the electric field $\boldsymbol{E}$ is defined as

$$
\boldsymbol{E}=\frac{p}{q_{e} \rho_{e}} \nabla\left(\frac{p_{e}}{p}\right)
$$

The electron diffusion flux $\boldsymbol{J}_{e}$ can then be calculated using Eq. (22).

In the SCEBD model, the expression for the effective diffusion coefficient given in Eq. (19) is replaced by

$$
D_{s \neq e}=\left(1-\frac{\omega_{s}}{\omega}\right)\left(\sum_{r \neq s, e} \frac{p_{r}}{p D_{s r}}\right)^{-1}
$$

where $\omega_{s} / \omega$ are weighting factors defined as

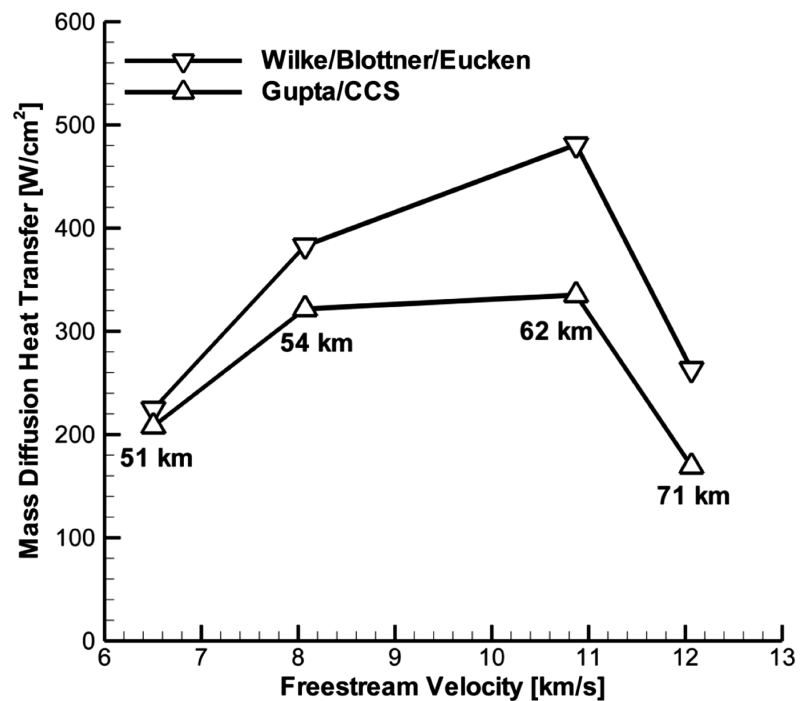

\section{b) Diffusive}



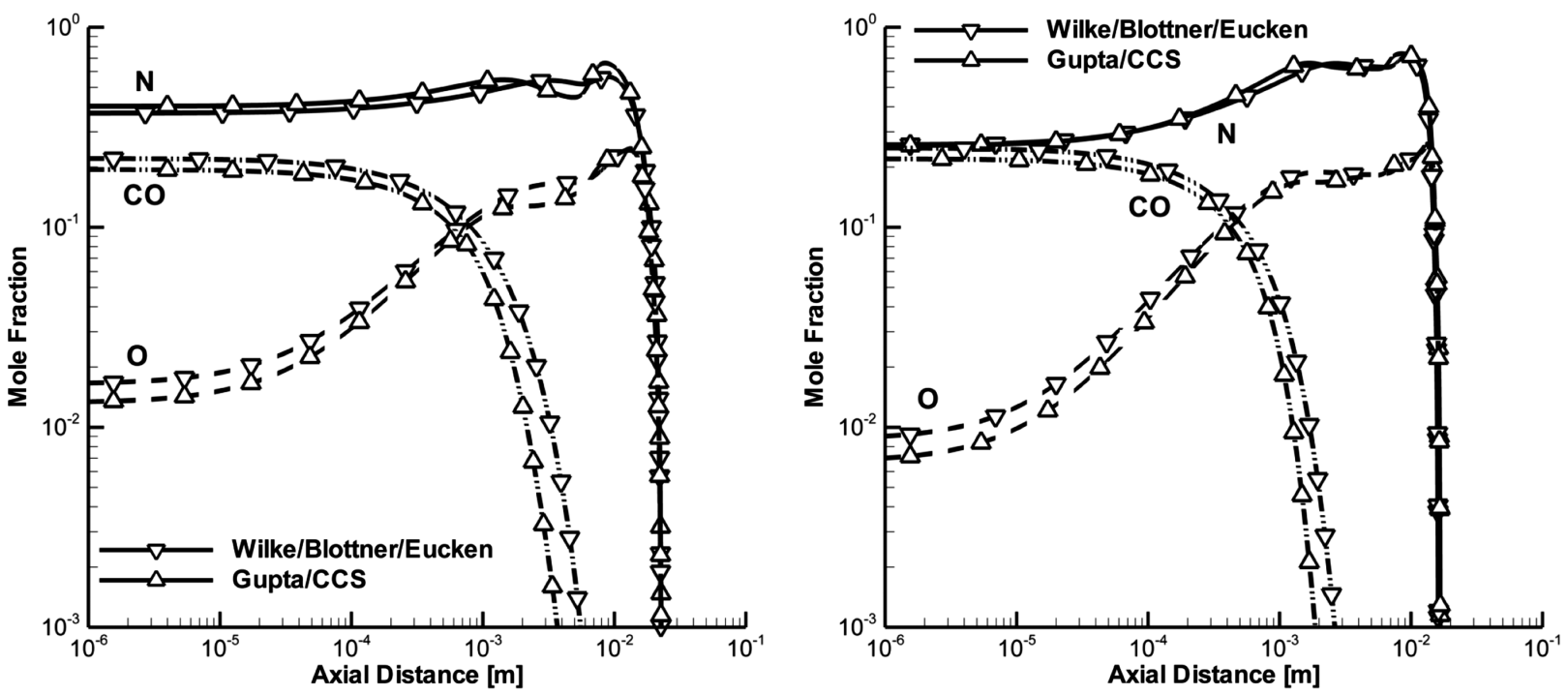

a) $71 \mathrm{~km}$

b) $62 \mathrm{~km}$
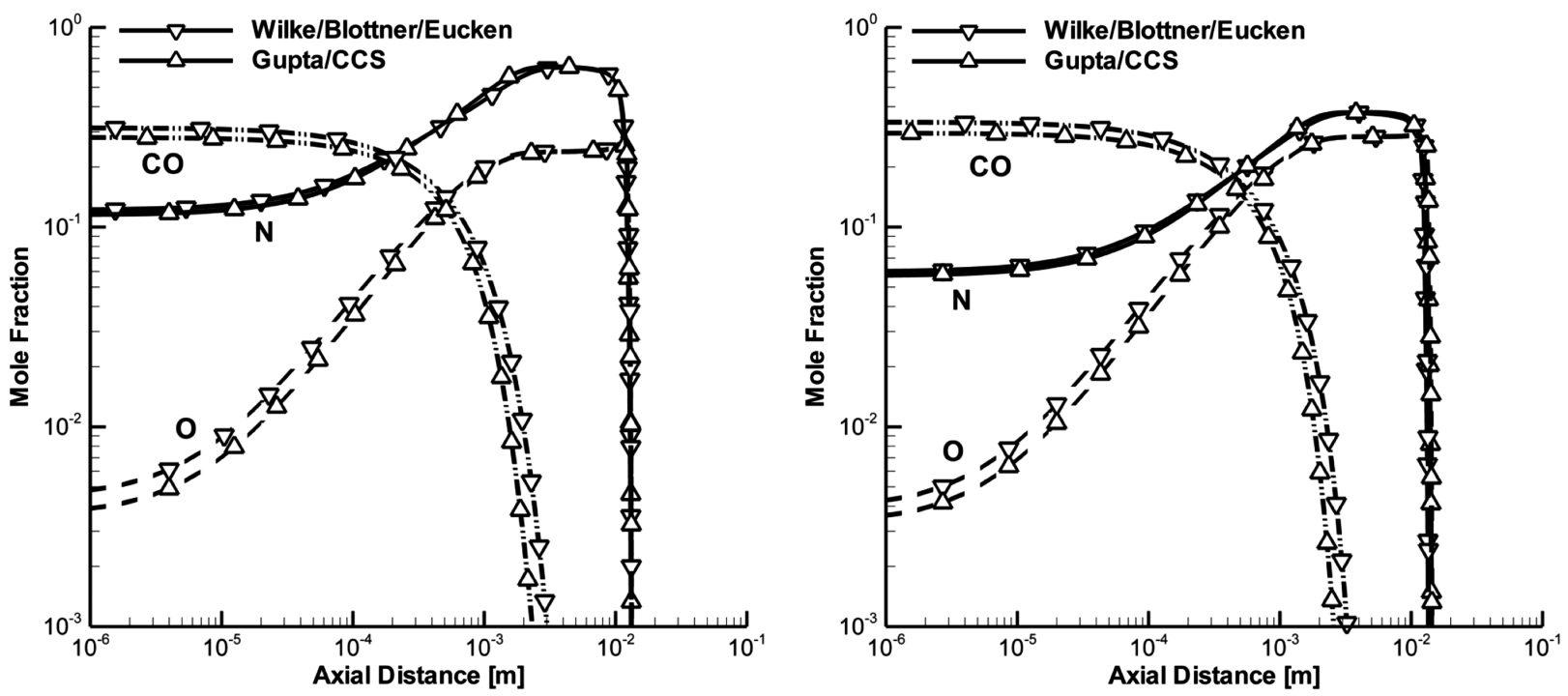

c) $54 \mathrm{~km}$

d) $51 \mathrm{~km}$

Fig. 6 Mole fraction distributions of N, O, and $\mathrm{CO}$ along the stagnation line away from the wall obtained using the Wilke/Blottner/Eucken and Gupta/ CCS models.

$$
\boldsymbol{J}_{s}=-\rho D_{s} \nabla Y_{s}+\frac{Y_{s}}{\left(1-X_{s}\right)} D_{s} \sum_{r \neq s}\left(\rho \frac{M}{M_{r}} \nabla Y_{r}+\frac{M}{M_{r}} \frac{J_{r}}{D_{s, r}}\right)
$$

Equation (29) is a set of $(N S-1)$ equations for $N S$ species; therefore, a closure relation is needed to find the mass diffusion fluxes. For this study, an iterative method is used to solve for the fluxes [1]. First, the mass flux for each heavy species is calculated at iteration $N$ using $[1,2]$

$\boldsymbol{J}_{s \neq e}^{N}=-\rho D_{s} \nabla Y_{s}+\frac{Y_{s}}{\left(1-X_{s}\right)} D_{s} \sum_{r \neq s, e}\left(\rho \frac{M}{M_{r}} \nabla Y_{r}+\frac{M}{M_{r}} \frac{\boldsymbol{J}_{r}^{N-1}}{D_{s, r}}\right)$

and then the entire set is corrected for iteration $N+1$ using the closure equation

$$
\boldsymbol{J}_{s \neq e}^{N+1}=\boldsymbol{J}_{s}^{N}-Y_{s} \sum_{r \neq e} \boldsymbol{J}_{r}^{N}
$$

The first term of Eq. (30) is used as the initial guess in the iteration process. The electron mass diffusion flux is then determined using Eq. (22). The Stefan-Maxwell model has been shown to accurately calculate the mass diffusion fluxes for multicomponent mixtures $[1,5]$ and is considered the most physically rigorous model in this study. One drawback of the Stefan-Maxwell model, however, is that it is computationally expensive and has been shown to require approximately $50 \%$ more time per CFD iteration than the other models [1].

\section{Test Case: Stardust Sample Return Capsule}

The Stardust payload was launched in 1999 on a mission to collect samples from interstellar dust and the tail of Comet Wild 2, and return them to Earth. The Stardust sample return capsule (SRC), shown schematically in Fig. 1a, landed in the Utah desert in January 2006. The Earth entry trajectory of the return capsule is presented in Fig. 1b. The Stardust spacecraft then continued its travel through the solar system, on a mission to image Comet Tempel 1. It was decommissioned after completing that final mission in March 2011. The Stardust mission represents the first ever return of a sample from a comet: a significant milestone in the human exploration of space. With an entry velocity of $12.6 \mathrm{~km} / \mathrm{s}$, the capsule was also the fastest manmade object ever to enter the Earth's atmosphere, providing a unique test case to evaluate numerical simulations. To protect the 

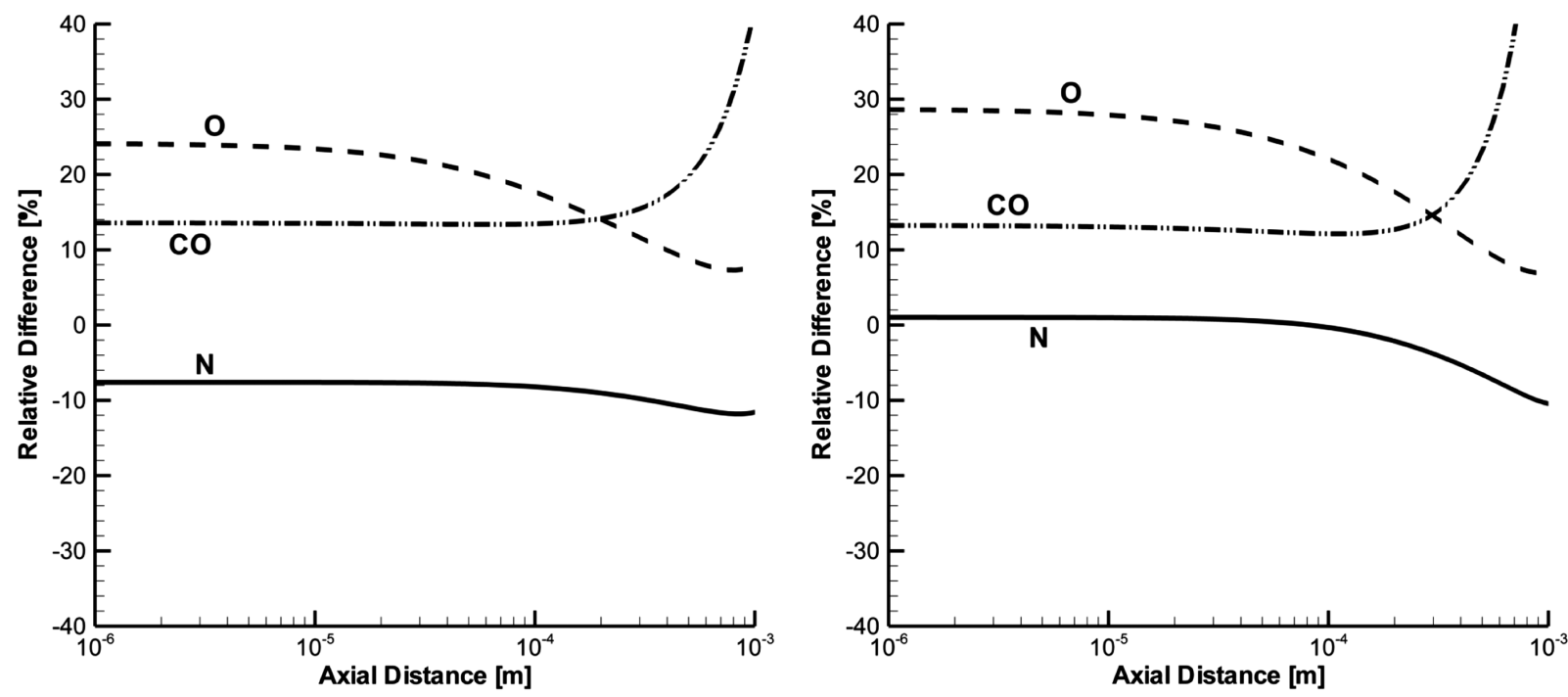

a) $71 \mathrm{~km}$

b) $62 \mathrm{~km}$
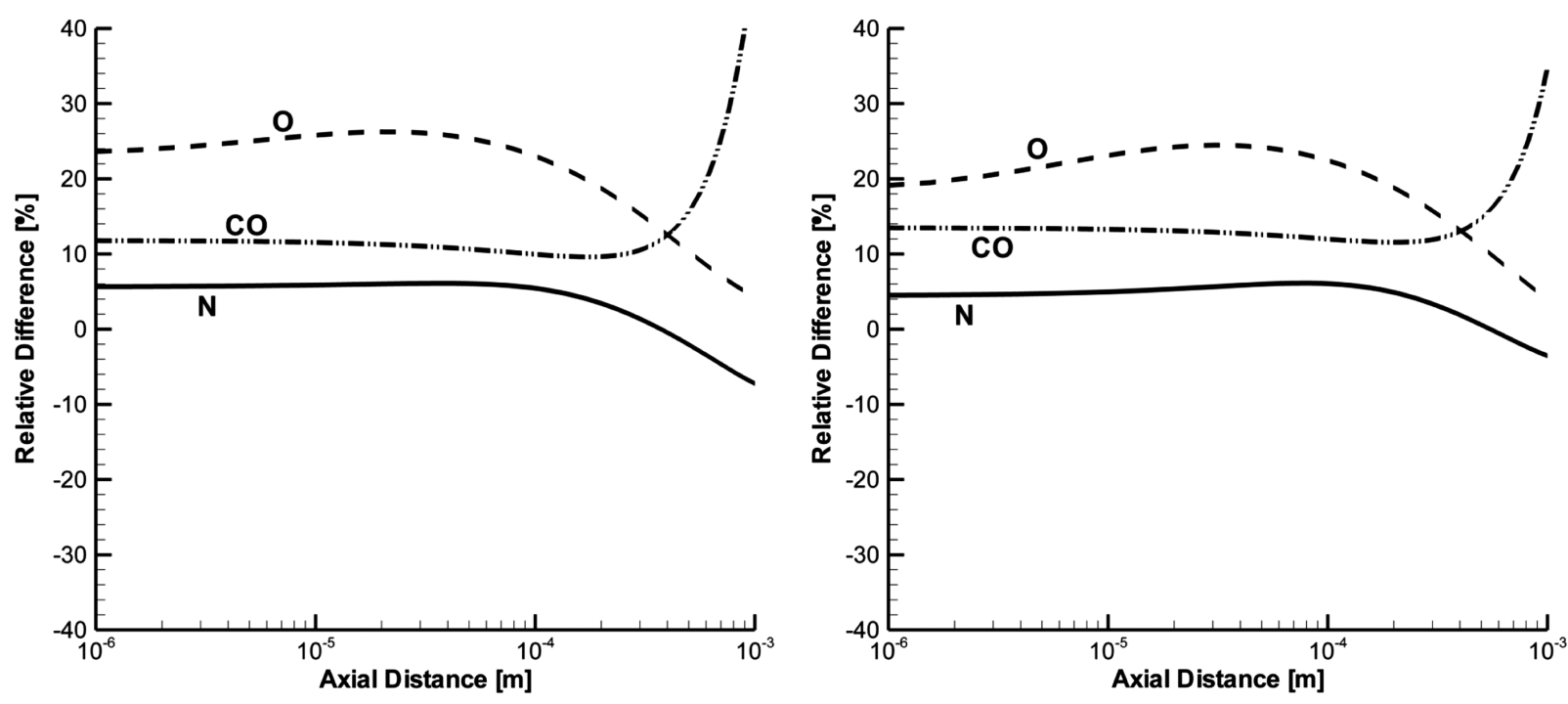

c) $54 \mathrm{~km}$

d) $51 \mathrm{~km}$

Fig. 7 Difference in $\mathrm{N}, \mathrm{O}$, and $\mathrm{CO}$ mole fractions along the stagnation line in the shock layer obtained using the Wilke/Blottner/Eucken relative to the Gupta/CCS model.

vehicle from the extreme entry conditions, the thermal protection system for the Stardust capsule used the phenolic-impregnated carbon ablator (PICA) [22], which is a lightweight material with a density of approximately $240 \mathrm{~kg} / \mathrm{m}^{3}$.

The freestream conditions simulated in this study are listed in Table 1 [23]. Peak heating occurs at an altitude of $62 \mathrm{~km}$ approximately $51 \mathrm{~s}$ after atmospheric entry. The chemistry model for the gas environment is adapted from [24-26] and consists of the following species:

$$
\begin{gathered}
\mathrm{N}_{2}, \mathrm{O}_{2}, \mathrm{NO}, \mathrm{N}, \mathrm{O}, \mathrm{N}_{2}^{+}, \mathrm{O}_{2}^{+}, \mathrm{NO}^{+}, \mathrm{N}^{+}, \mathrm{O}^{+}, \mathrm{e} \\
\mathrm{C}, \mathrm{C}_{2}, \mathrm{C}_{3}, \mathrm{CO}, \mathrm{CO}_{2}, \mathrm{CN}, \mathrm{CO}^{+}, \mathrm{C}^{+}
\end{gathered}
$$

The constants used in Blottner's curve fits [i.e., Eq. (3)] for the gas-phase species considered in this study are presented in Table 2. These constants are determined using the commercial software CHEMKIN to produce temperature-dependent viscosity curve fits for each individual species $[25,26]$. The collision integrals used in this study are based on the data collected by Wright et al. in [17,18]. The accuracy of these collision integrals varies depending on the collision pair and is given in $[17,18]$. Most of the dominant atom-atom interactions are derived from ab initio calculations. Alternate sources, such as beam-scattering experiments, are used when such ab initio calculations do not exist. The collision integrals involving ions and neutrals are based on the polarization (Langevin) potential, which is a function only of dipole polarizability of the neutral species and the temperature ([18] Eqs. 2 and 3). For interactions between two charged particles (electron-electron, electron-ion, and ion-ion), the collision integrals are calculated using attractive and repulsive shielded coulomb potentials ([17] Eq. 6). Additional information regarding the methods used to obtain the collision integrals used in this study can be found in $[17,18]$.

Table 3 presents the chemical mechanisms that are assumed to occur at the surface of the Stardust SRC. These mechanisms were developed by Driver et al. by comparing CFD predictions to heat transfer and recession rate measurements obtained at an arcjet facility for PICA [27,28]. The mechanisms found by Driver et al. included the oxidation of bulk carbon by atomic oxygen with a constant reaction efficiency of $\gamma=0.90$ and the oxidation of bulk carbon by molecular oxygen with a constant efficiency of $\gamma=0.01$. These mechanisms also included the recombination of atomic nitrogen at 


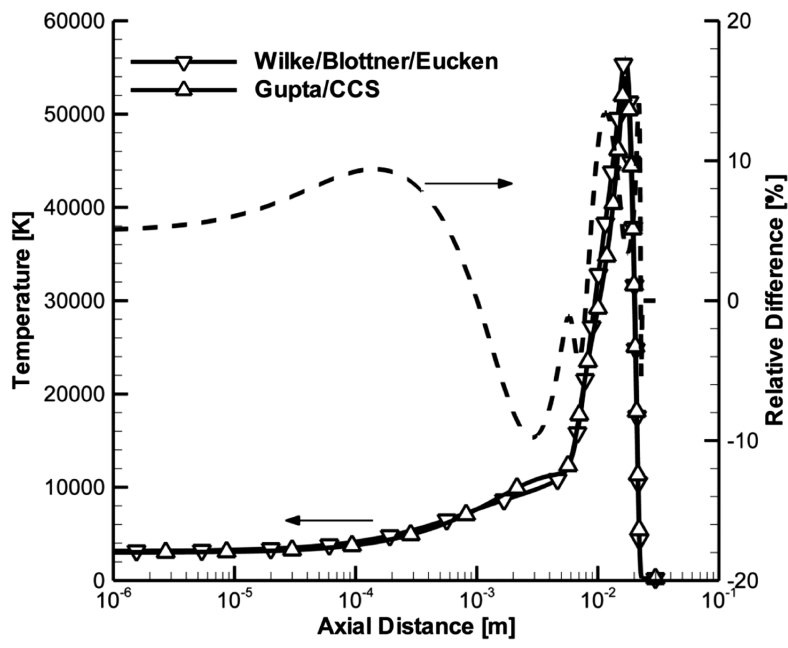

a) $71 \mathrm{~km}$

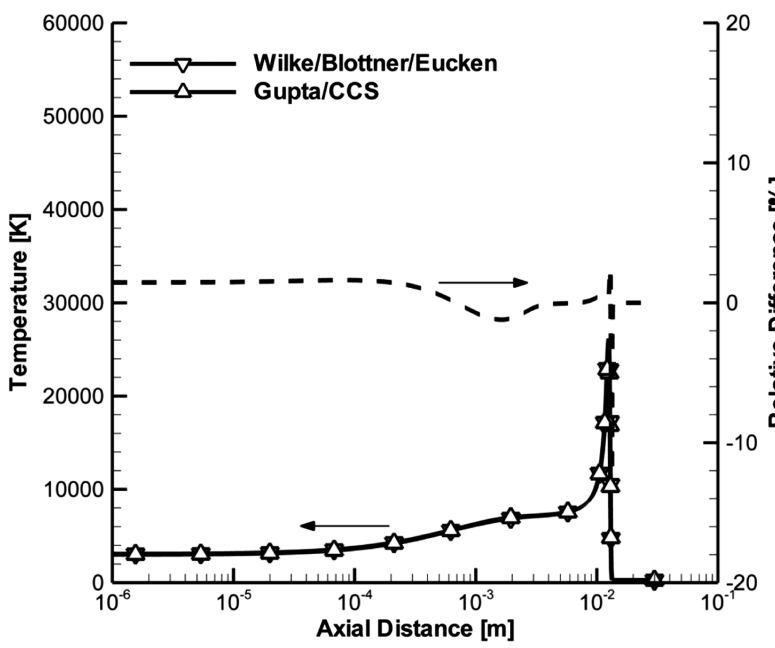

c) $54 \mathrm{~km}$

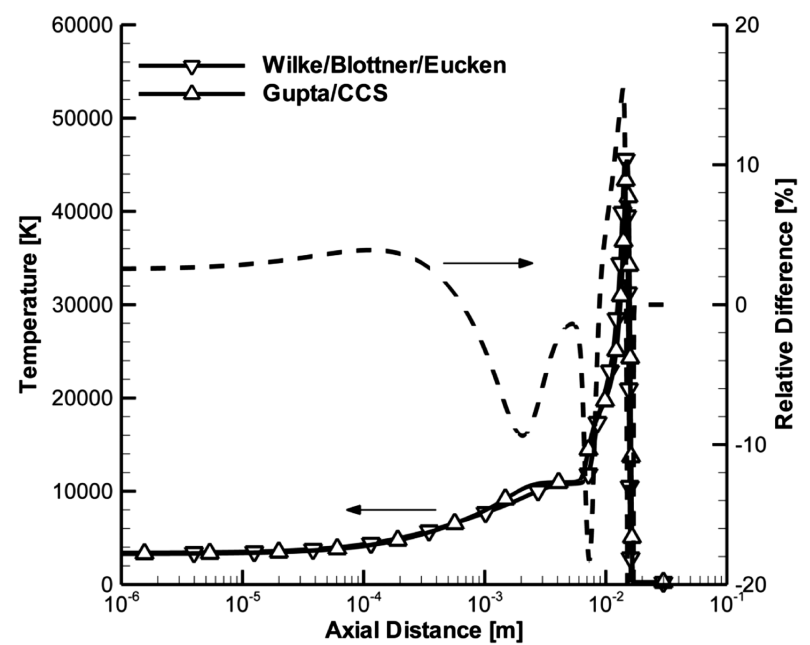

b) $62 \mathrm{~km}$

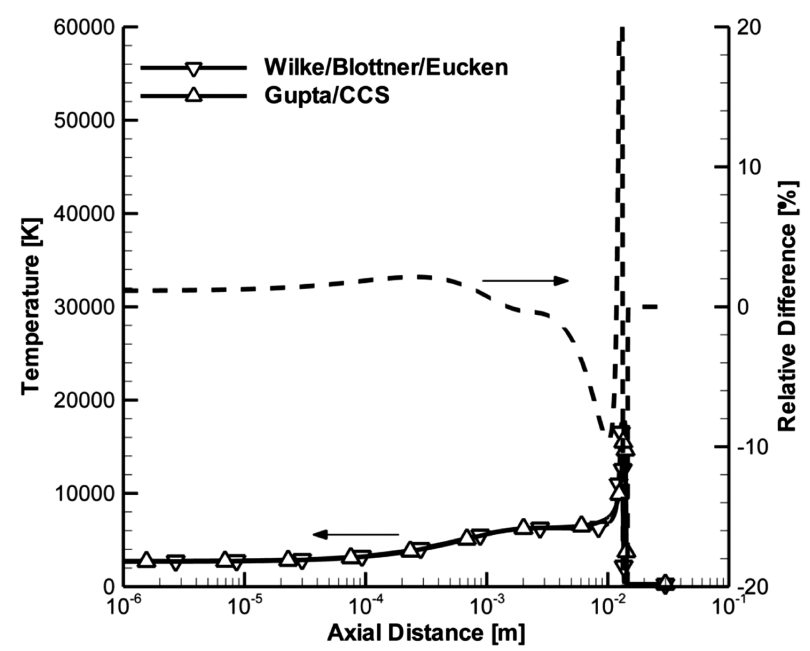

d) $51 \mathrm{~km}$

Fig. 8 Translational temperature distribution along the stagnation line away from the wall obtained using the Wilke/Blottner/Eucken and Gupta/CCS models.

the surface with a constant recombination efficiency of $\gamma=0.05$. Table $\underline{3}$ also presents the heat released by these exothermic surface reactions.

The surface material of the Stardust entry capsule for this study is assumed to be FiberForm instead of PICA. FiberForm is the substrate from which PICA is processed, and it has been shown to have approximately the same properties as the char layer of PICA [29]. This assumption is chosen to neglect the effects of pyrolysis gases emitted from the surface, since FiberForm does not contain phenolic. The density of the bulk environment is assumed to be equal to $180 \mathrm{~kg} / \mathrm{m}^{3}$, which is the density of FiberForm and PICA close to the char exterior surface [29]. The surface temperature is calculated assuming radiative equilibrium at the wall with an emissivity of 0.9 . The entry of the Stardust SRC was nearly ballistic [30]. Therefore, a two-dimensional axisymmetric grid is used in this study. The grid is composed of approximately 96,000 quadrilateral cells in the forebody region, with approximately 300 cells in the axial direction and 320 cells in the radial direction along the SRC forebody. Clustering is used near the capsule surface, and the size of the first grid cell from the wall is $10^{-6} \mathrm{~m}$. A grid convergence study revealed that the solutions obtained using this mesh resolution are grid independent based on the stagnation point heat transfer, as can be seen in Fig. 2.

\section{Results}

The goal of this study is to evaluate the effects of different models for transport phenomena used in CFD codes on the flowfield predictions of ablative heat shields. The numerical results are presented in two sections. The first section discusses the effects of the model for the mixture transport coefficients (viscosity, thermal conductivity, and mass diffusion) on the flowfield solutions of the Stardust SRC using the Wilke/Blottner/Eucken and Gupta/CCS models. The species mass diffusion fluxes for both sets of cases are calculated using the modified Fick's model. The second part describes the effects of the mass diffusion model on the Stardust SRC solutions using the Fick's, modified Fick's, SCEBD, and StefanMaxwell models. The transport coefficients are calculated using the Gupta/CCS model in the second portion of the study.

\section{A. Mixture Transport Coefficients}

Figure 3 presents the stagnation point heat transfer to the Stardust SRC as a function of freestream velocity calculated using the Wilke/ Blottner/Eucken and Gupta/CCS models. Figure 3a shows the solution obtained using the surface chemistry mechanisms given in Table 3, whereas Fig. 3b shows the noncatalytic wall solution with no surface reactions. For the finite-rate surface chemistry solution, the heat transfer obtained using the Wilke/Blottner/Eucken model is in good agreement with the Gupta/CCS solution for the $51 \mathrm{~km}$ conditions. However, the Wilke/Blottner/Eucken model produces larger heat transfer relative to the Gupta/CCS model by about $15 \%$ for $54 \mathrm{~km}, 35 \%$ for $62 \mathrm{~km}$, and $60 \%$ for $71 \mathrm{~km}$. The noncatalytic wall solution follows a similar trend, as can be seen in Fig. $3 \mathrm{~b}$. However, the difference in the heat transfer predicted using the 


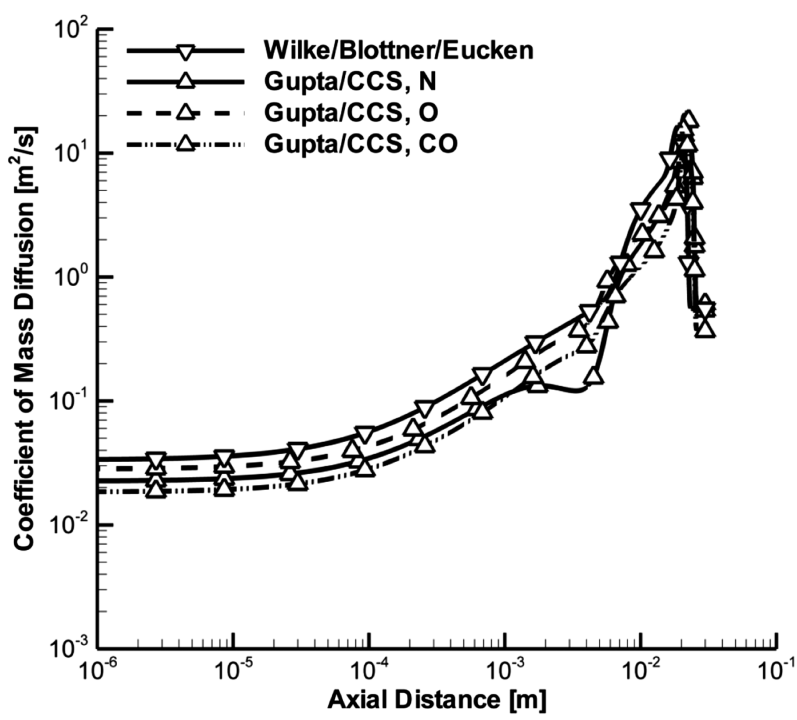

a) $71 \mathrm{~km}$

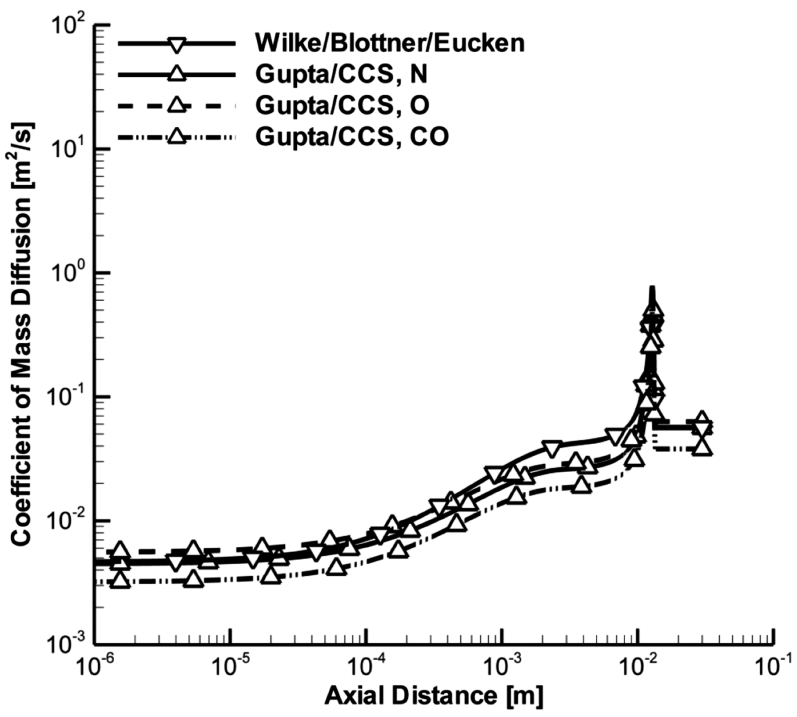

c) $54 \mathrm{~km}$

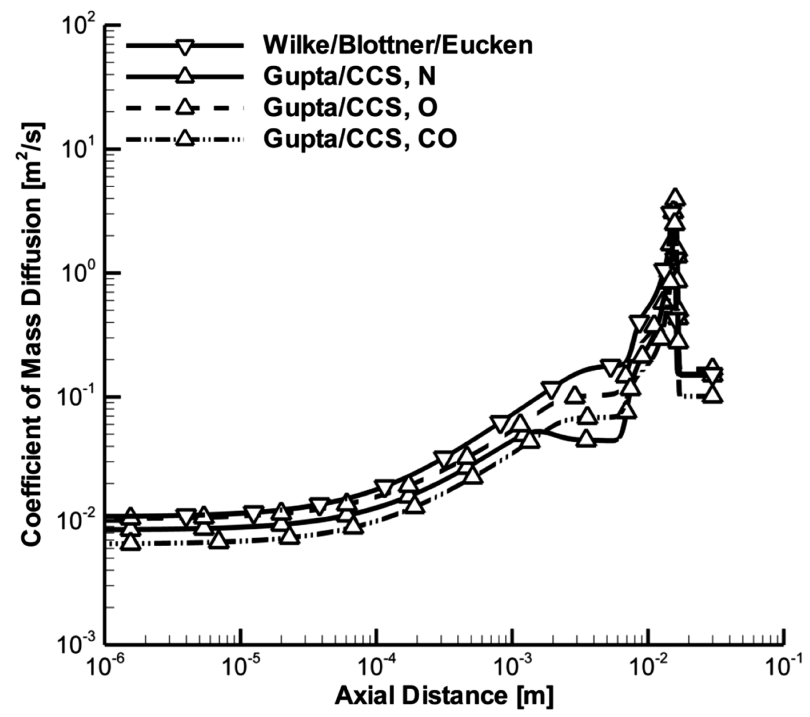

b) $62 \mathrm{~km}$

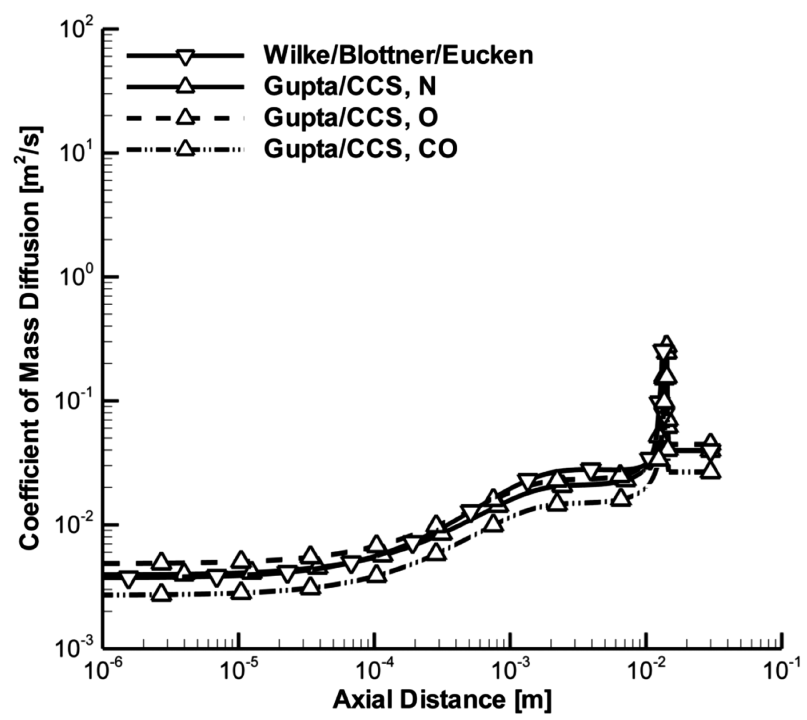

d) $51 \mathrm{~km}$

Fig. 9 Effective diffusion coefficients of $\mathbf{N}, \mathbf{O}$, and $\mathrm{CO}$ along the stagnation line away from the wall calculated using the Wilke/Blottner/Eucken and Gupta/CCS models.

Wilke/Blottner/Eucken and Gupta/CCS models is smaller for the noncatalytic wall. This result shows that the transport coefficients model can have a significant effect on the predicted heat transfer for ablative heat shields.

The heat transfer to the Stardust SRC surface includes the contribution due to temperature gradients (convective) and the diffusion of species that can react at the surface and in the boundary layer to release heat (diffusive). Figure $\underline{4}$ presents the convective and diffusive heat transfer components at the stagnation point as functions of freestream velocity calculated using the Wilke/Blottner/ Eucken and Gupta/CCS models. Figure 4a shows that the transport models produce similar convective heat transfer for the 51 and $54 \mathrm{~km}$ conditions. However, the Wilke/Blottner/Eucken model produces a greater convective heat transfer compared to the Gupta/CCS model for the 62 and $71 \mathrm{~km}$ trajectory points by about 20 and $60 \%$, respectively. The Wilke/Blottner/Eucken model also produces a larger diffusive heat transfer relative to the Gupta/CCS model, as can be seen in Fig. 4b. The difference in the predicted diffusive heat transfer varies from about $10 \%$ for the $51 \mathrm{~km}$ conditions to $60 \%$ for the $71 \mathrm{~km}$ conditions. This difference in the diffusive component between the Wilke/Blottner/Eucken and Gupta/CCS models increases the disagreement in the heat transfer between the two models compared to the noncatalytic wall solution, as can be seen in Fig. 3.

The removal of bulk carbon due to the oxidation reactions (Table 3 ) produces an effective mass blowing at the surface. The rate of this mass blowing at the stagnation point calculated using the Wilke/ Blottner/Eucken and Gupta/CCS models is presented in Fig. 5. The blowing rate calculated using the Wilke/Blottner/Eucken model is larger than the rate obtained using the Gupta/CCS model for all of the trajectory conditions considered in this study. The difference in the blowing rate between the two models varies from about $15 \%$ for the $51 \mathrm{~km}$ case to about $25 \%$ for the $62 \mathrm{~km}$ conditions. The mass blowing rate is proportional to the oxidation rate of bulk carbon. The larger rate obtained using the Wilke/Blottner/Eucken model indicates that more oxygen atoms and molecules react at the surface to form CO compared to the Gupta/CCS model. Since these oxidation reactions are exothermic, more heat is released in the form of enthalpy of formation for the Wilke/Blottner/Eucken model compared to the Gupta/CCS model, which contributes to a larger heat transfer to the surface, as shown in Fig. $3 \mathrm{a}$.

Figure 6 presents the mole fraction distributions of $\mathrm{N}, \mathrm{O}$, and $\mathrm{CO}$ through the shock layer along the stagnation line obtained using the Wilke/Blottner/Eucken and Gupta/CCS models. The difference in 

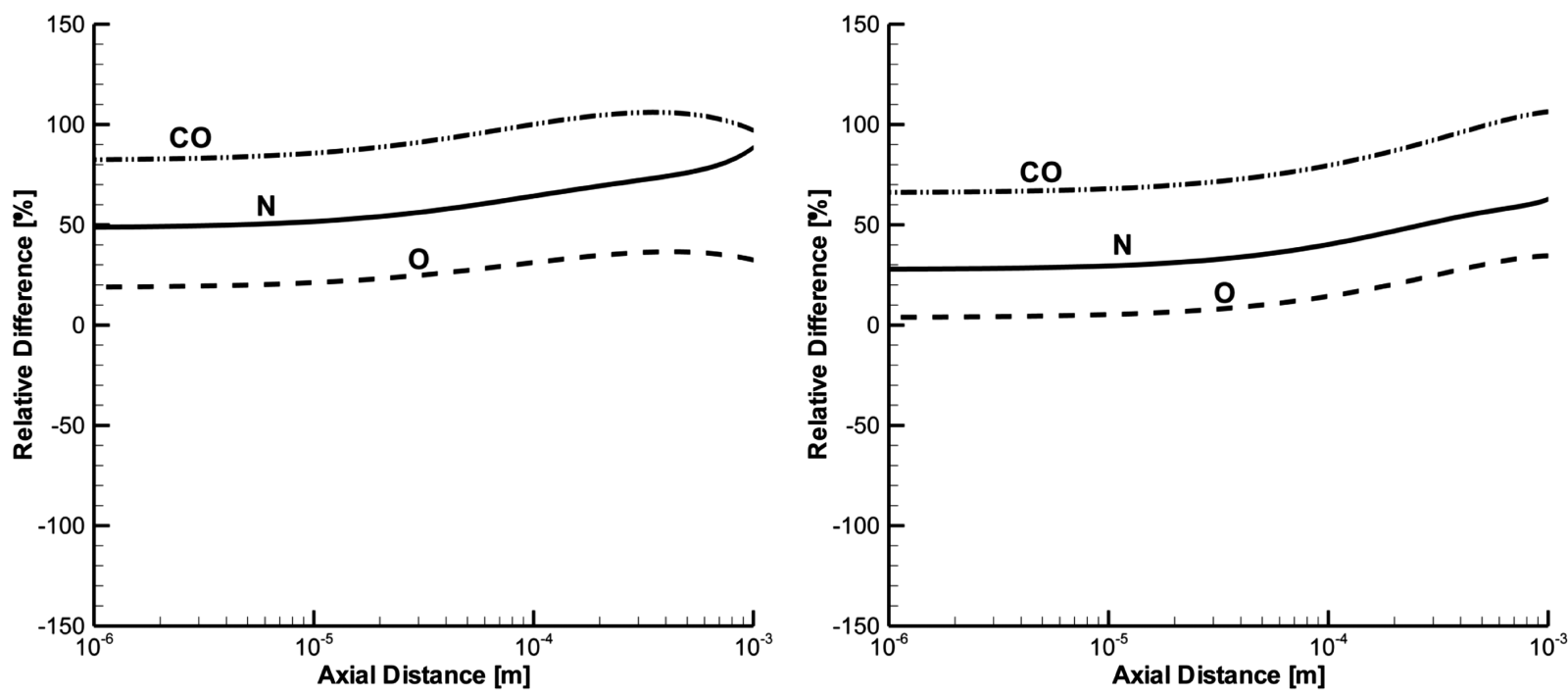

a) $71 \mathrm{~km}$

b) $62 \mathrm{~km}$
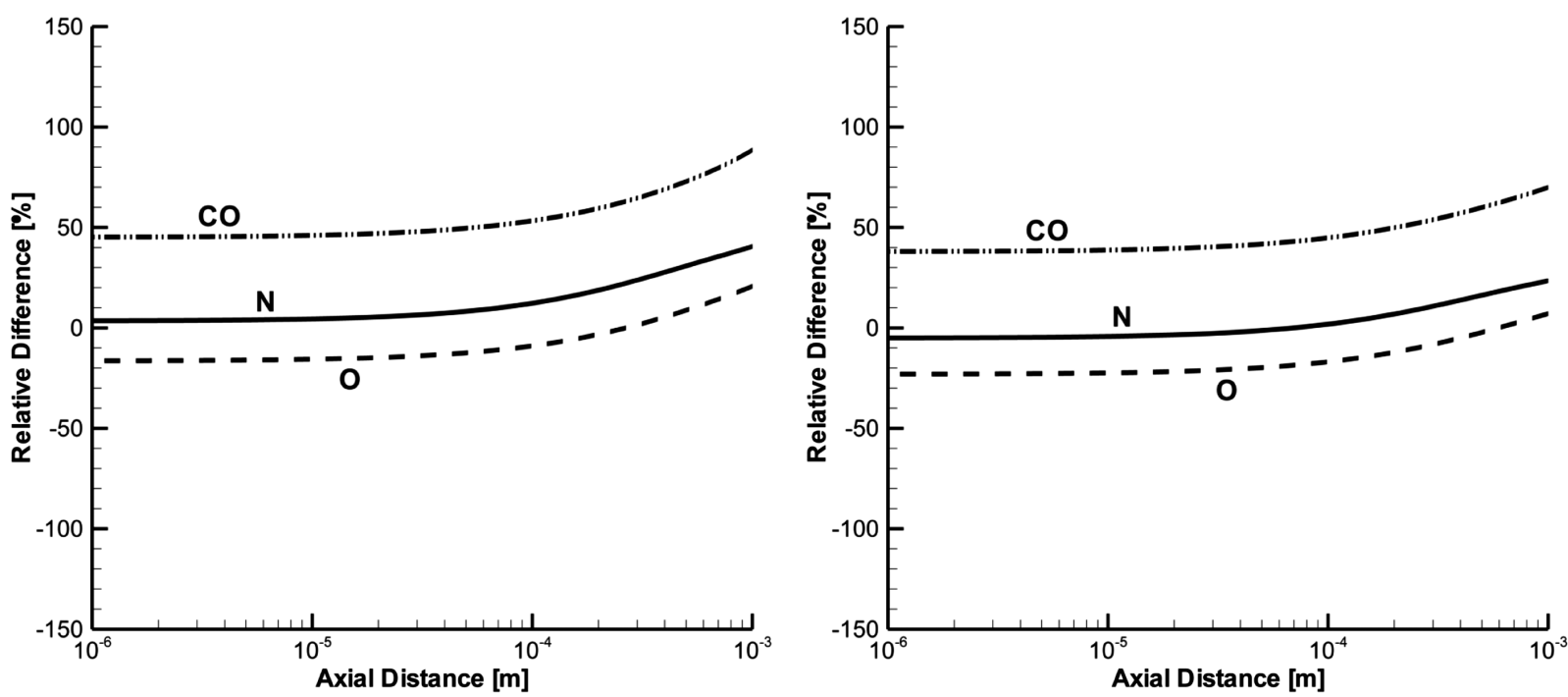

c) $54 \mathrm{~km}$

d) $51 \mathrm{~km}$

Fig. 10 Difference in the effective diffusion coefficients of $\mathrm{N}, \mathrm{O}$, and $\mathrm{CO}$ along the stagnation line in the shock layer obtained using the Wilke/Blottner/ Eucken model relative to the Gupta/CCS model.

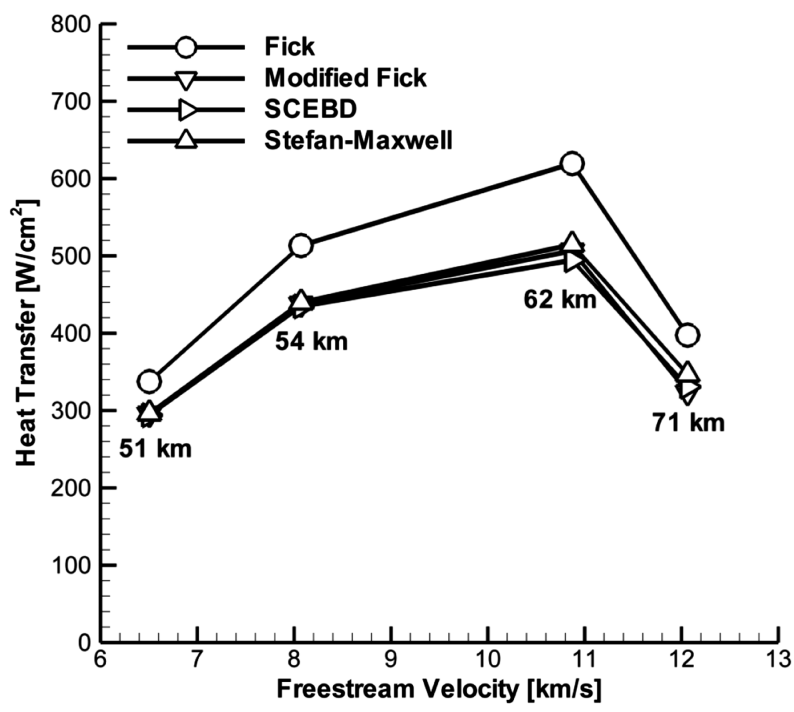

a) Finite-rate surface chemistry

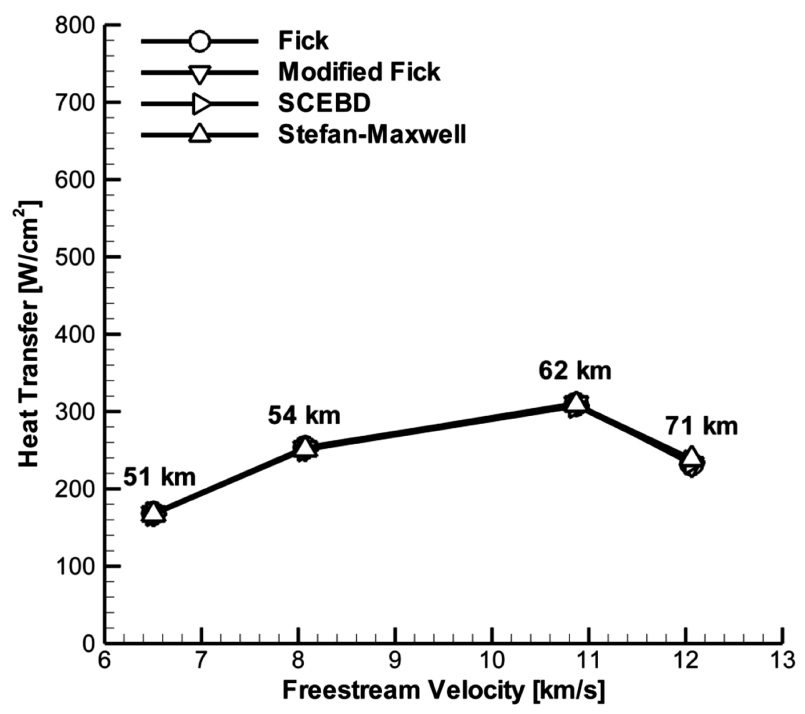

b) Noncatalytic wall

Fig. 11 Stagnation point heat transfer calculated using the Fick's, modified Fick's, SCEBD, and Stefan-Maxwell models. 


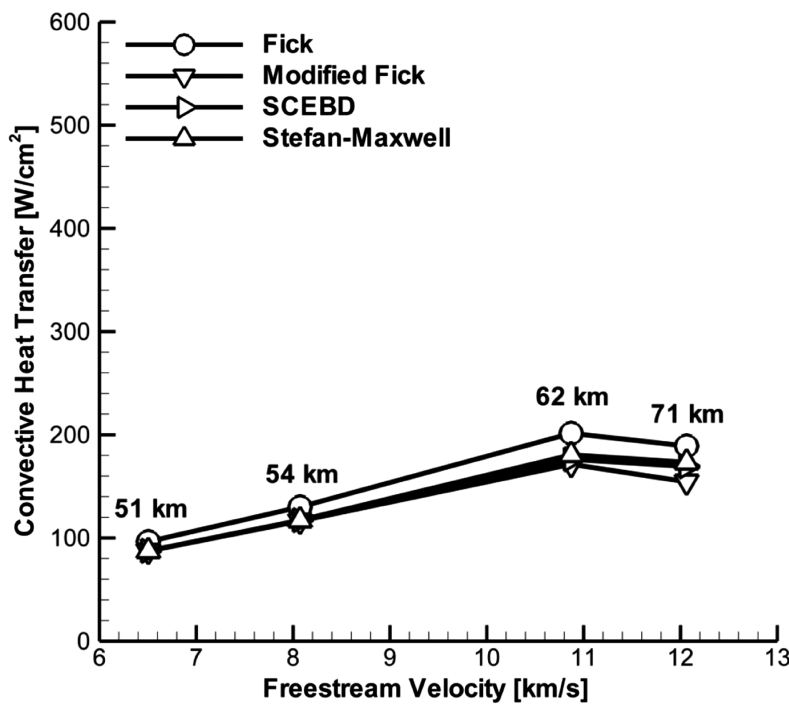

a) Convective

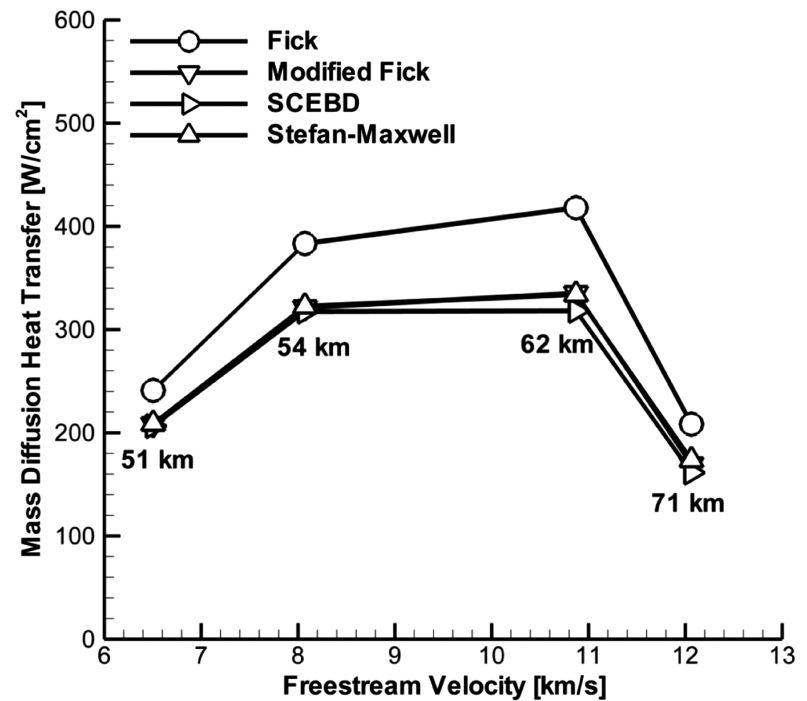

b) Diffusive

Fig. 12 Convective and diffusive stagnation point heat transfer calculated using the Fick's, modified Fick's, SCEBD, and Stefan-Maxwell models.

the mole fractions obtained using the Wilke/Blottner/Eucken model relative to the Gupta/CCS/model in the shock layer are shown in Fig. 7. Figures $6 \mathrm{a}$ and $6 \mathrm{~b}$ show some disagreement in the $\mathrm{N}$ and $\mathrm{O}$ distributions calculated using the two models directly downstream of the shock for the 71 and $62 \mathrm{~km}$ conditions. This disagreement decreases for the 54 and $51 \mathrm{~km}$ trajectory points, but there is still a difference of about $20 \%$ in the $\mathrm{O}$ mole fraction in the shock layer calculated using the two models. The larger oxygen mole fraction obtained using the Wilke/Blottner/Eucken model in the boundary layer increases the production rate of $\mathrm{CO}$ at the surface, which increases the mass blowing rate relative to the Gupta/CCS model. Although not shown, the results obtained using the two models off the stagnation line follow similar trends.

The accuracy of Wilke's mixing rule has been shown to deteriorate for temperatures above approximately $10,000 \mathrm{~K}$ [4]. Figure 8 shows the translational temperature distribution along the stagnation line calculated using the Wilke/Blottner/Eucken and Gupta/CCS models. The peak temperature along the stagnation line predicted using the two models increases from about $20,000 \mathrm{~K}$ for the $51 \mathrm{~km}$ trajectory point to about $60,000 \mathrm{~K}$ for the $71 \mathrm{~km}$ point. Previous studies have shown that the accuracy of Wilke's mixing rule decreases as the temperature increases above approximately $10,000 \mathrm{~K}[\underline{4}, 5]$. In the context of the current study, the accuracy of the Wilke/Blottner/ Eucken model decreases as the altitude of the trajectory points increases, which contributes to the differences in the heat transfer shown in Fig. 4.

Figure 9 presents the effective mass diffusion coefficient of $\mathrm{N}, \mathrm{O}$, and $\mathrm{CO}$ along the stagnation line obtained using the Wilke/Blottner/ Eucken and Gupta/CCS models. The relative difference in the mass diffusion coefficients for these species are shown in Fig. 10. Note that a single effective diffusion coefficient is defined for all of the species for the Wilke/Blottner/Eucken model [Eq. (5)]. The results show that the effective diffusion coefficients calculated using the Gupta/ CCS model are different for each species. The effective diffusion coefficient obtained using the Wilke/Blottner/Eucken model provides a reasonable approximation of the effective coefficients of $\mathrm{N}$, $\mathrm{O}$, and $\mathrm{CO}$ calculated using the Gupta/CCS model for the 54 and $51 \mathrm{~km}$ conditions because the effective coefficients of these species are close. The difference between the effective diffusion coefficients calculated using the two models increases for the 71 and $62 \mathrm{~km}$ conditions. For instance, the difference in the effective diffusion coefficient of $\mathrm{N}$ in the shock layer for the $62 \mathrm{~km}$ case is between 30 and 50\%, as can be seen in Fig. 10b. The differences in the effective diffusion coefficients obtained using the two transport models also contribute to the disagreement in the aerothermal properties of the Stardust SRC.

\section{B. Mass Diffusion}

In the second part of the study, the effects of the mass diffusion model on the flowfield predictions of the Stardust SRC are evaluated. Figure 11 presents the stagnation point heat transfer for the trajectory conditions considered in this study calculated using the Fick's, modified Fick's, SCEBD, and Stefan-Maxwell models. The heat transfer calculated using the modified Fick's and SCEBD models are within $3 \%$ of the solution obtained using the Stefan-Maxwell model. The stagnation point heat transfer is larger for the Fick's models compared to the other models by as much as $20 \%$ for the $62 \mathrm{~km}$ conditions. In addition to the heat transfer calculated assuming finiterate chemistry at the surface (Table 3 ), Fig. $11 \mathrm{~b}$ also presents the noncatalytic wall solution for comparison. Unlike the finite-rate surface chemistry solution, the heat transfer for the noncatalytic wall is not affected by the mass diffusion model for all of the entry conditions investigated in this study.

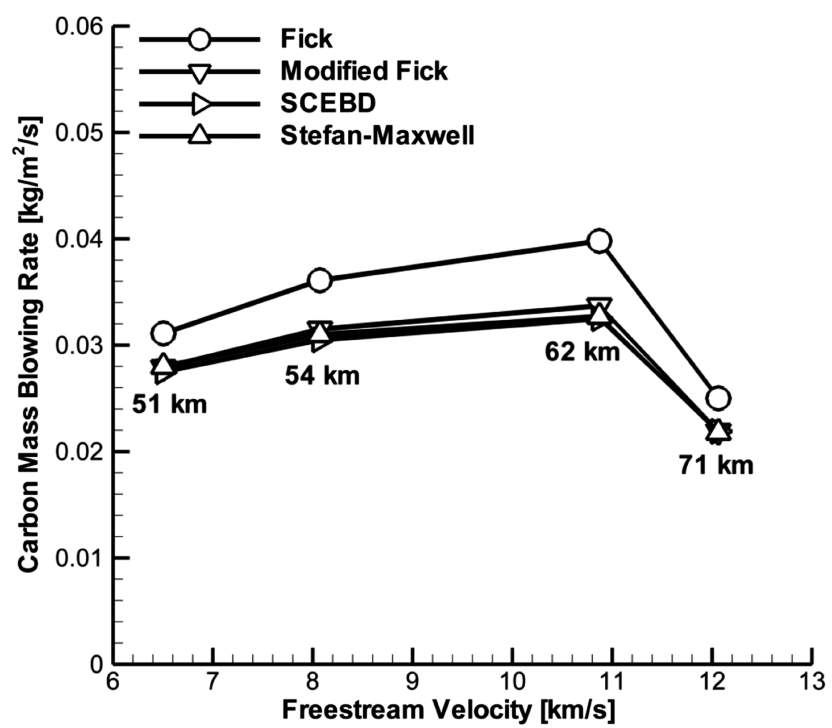

Fig. 13 Mass blowing rate due to carbon oxidation calculated using the Fick's, modified Fick's, SCEBD, and Stefan-Maxwell models. 

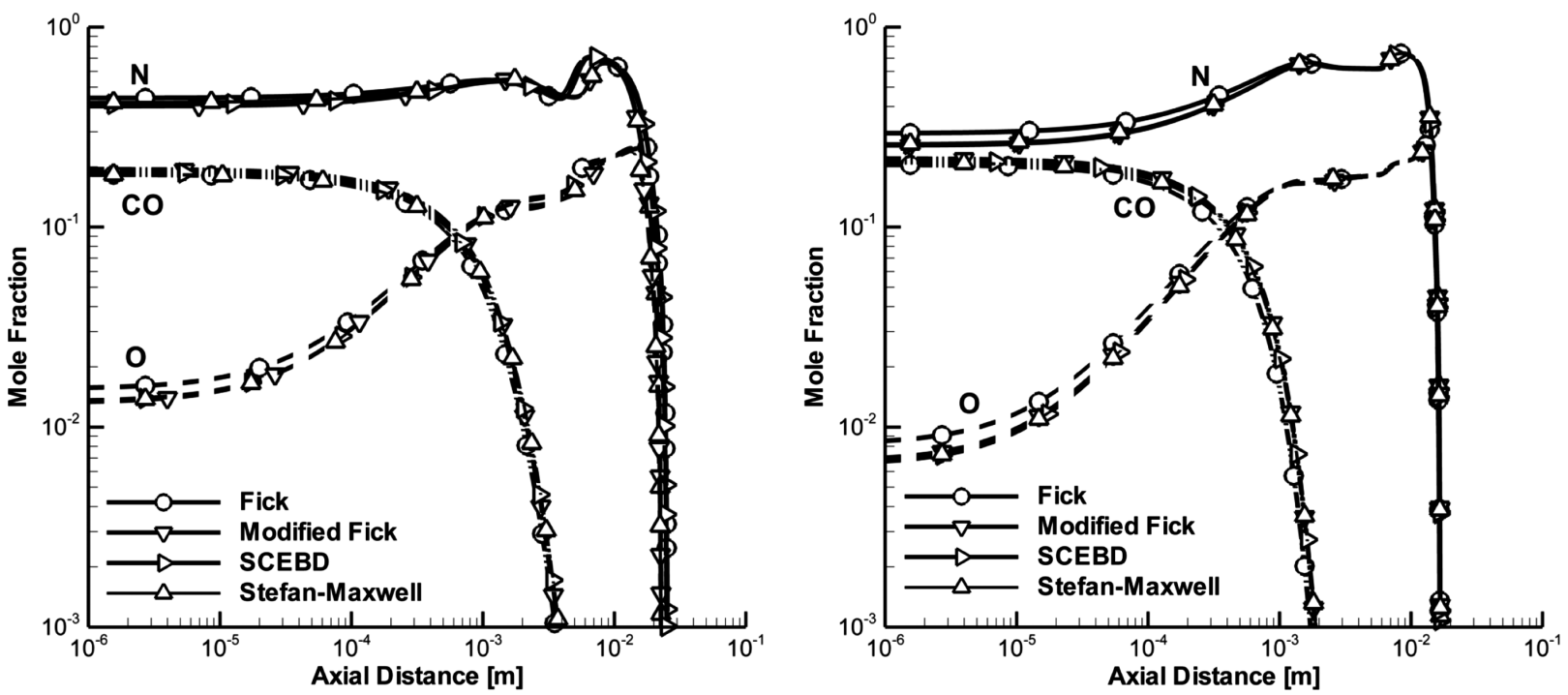

a) $71 \mathrm{~km}$

b) $62 \mathrm{~km}$
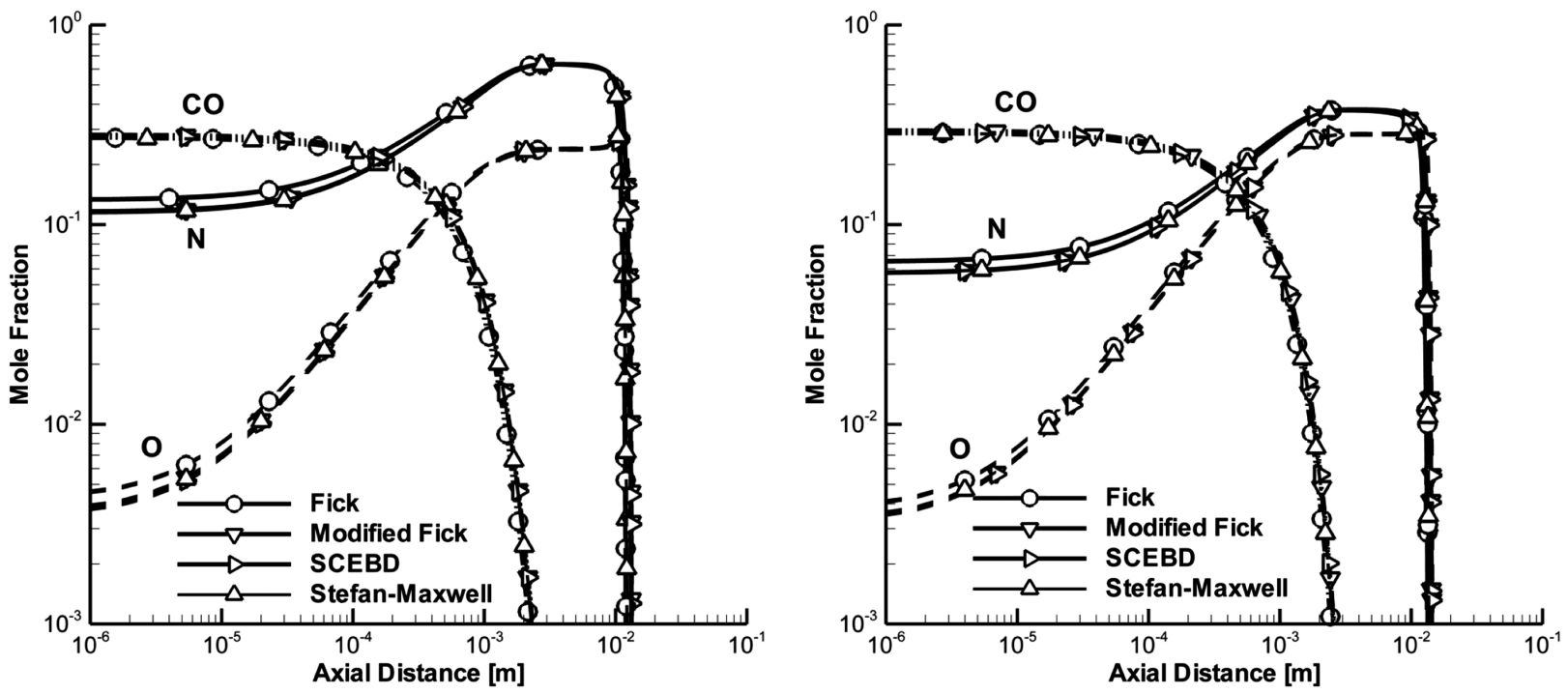

c) $54 \mathrm{~km}$

d) $51 \mathrm{~km}$

Fig. 14 Mole fraction distributions of N, O, and $\mathrm{CO}$ along the stagnation line away from the wall obtained using the Fick's, modified Fick's, SCEBD, and Stefan-Maxwell models.

The convective and diffusive components of the heat transfer at the stagnation point are presented in Fig. 12. Figure 12a shows that the convective heat transfer obtained using the modified Fick's, SCEBD, and Stefan-Maxwell models are in good agreement. The Fick's model produces an overall $10 \%$ larger convective heat transfer relative to the Stefan-Maxwell model. This difference in the convective heat transfer, however, is relatively small compared to the difference in the diffusive heat transfer shown in Fig. 12b. The diffusive heat transfer obtained using the Fick's model is greater relative to the Stefan-Maxwell solution by as much as $25 \%(62 \mathrm{~km})$. This difference in the diffusive heat transfer causes the disagreement in the stagnation point heat transfer shown in Fig. 11a.

The mass blowing rate due to the removal of bulk carbon by the oxidation mechanisms (Table 3) calculated using the Fick's, modified Fick's, SCEBD, and Stefan-Maxwell models is shown in Fig. 13. Similar to the heat transfer results, the mass blowing rates obtained using the modified Fick's, SCEBD, and StefanMaxwell models are in good agreement. The Fick's model, however, predicts a larger mass blowing rate for all of the trajectory conditions considered in this study. The largest difference in the mass blowing rate between the Fick's model and the Stefan-Maxwell model is approximately $20 \%$ for the $62 \mathrm{~km}$ conditions. This larger mass blowing rate again indicates that the heat released by the oxidation reactions is greater for the Fick's model, which contributes to the larger heat transfer to the SRC surface, shown in Fig. 11a.

The mole fraction distributions of $\mathrm{N}, \mathrm{O}$, and $\mathrm{CO}$ along the stagnation line calculated using the four mass diffusion models considered in this study are presented in Fig. 14, and the differences relative to the Stefan-Maxwell model are shown in Fig. 15. The mole fraction in the shock layer obtained using the modified Fick's, SCEBD, and Stefan-Maxwell models are in overall good agreement. The $\mathrm{CO}$ mole fraction near the stagnation point calculated using the Fick's model is similar to the StefanMaxwell solution. However, the mole fractions of $\mathrm{N}$ and $\mathrm{O}$ calculated using the Fick's model are larger relative to the Stefan-Maxwell solution. This disagreement in the mole fractions calculated using the Fick's model compared to the Stefan-Maxwell model increases the recombination of $\mathrm{N}$ (to form $\mathrm{N}_{2}$ ) and $\mathrm{O}$ (to form $\mathrm{CO}$ ) at the surface, releasing heat and increasing the diffusive heat transfer, as shown in Fig. 12b. Although not shown, the results obtained using these diffusion models off the stagnation line follow similar trends. 


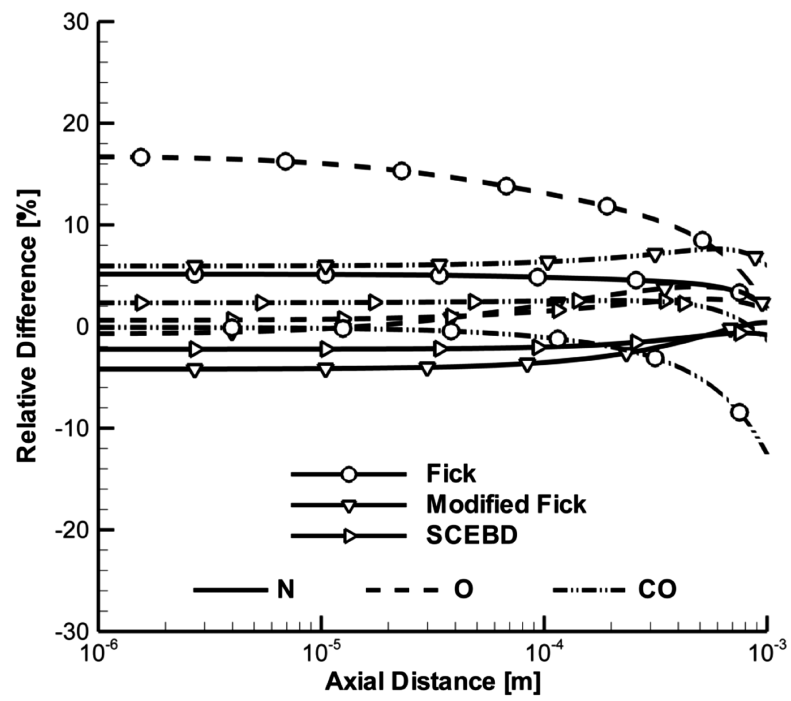

a) $71 \mathrm{~km}$

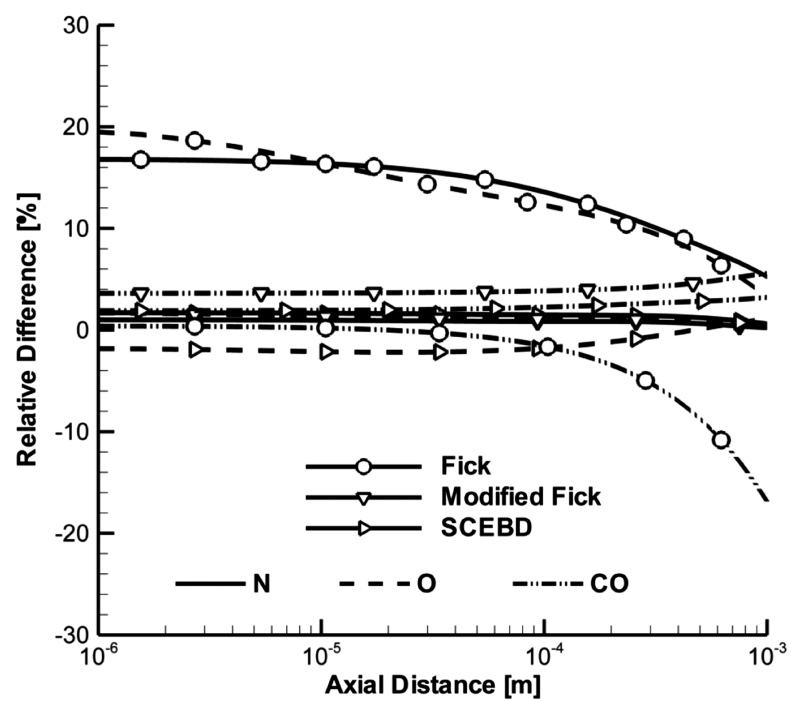

c) $54 \mathrm{~km}$

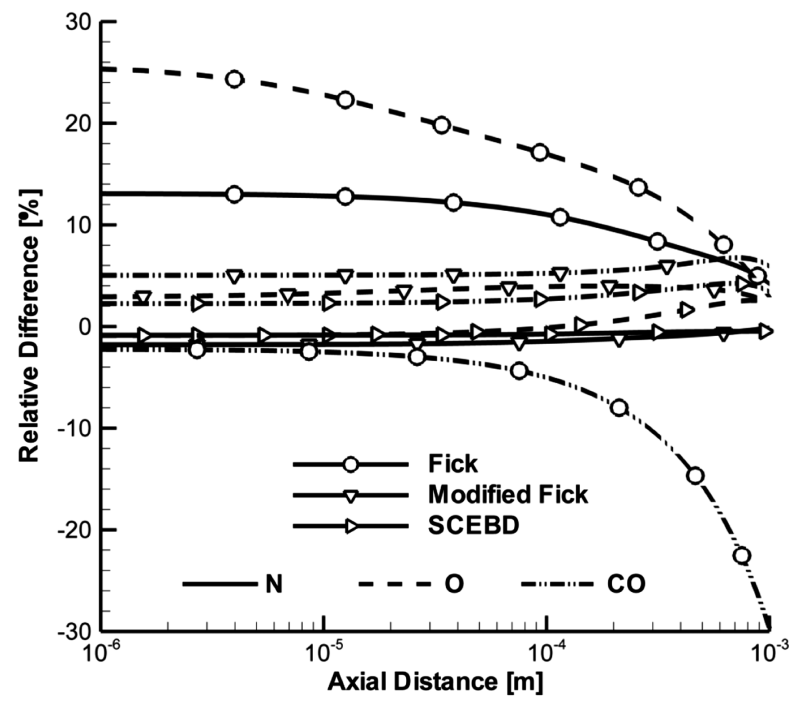

b) $62 \mathrm{~km}$

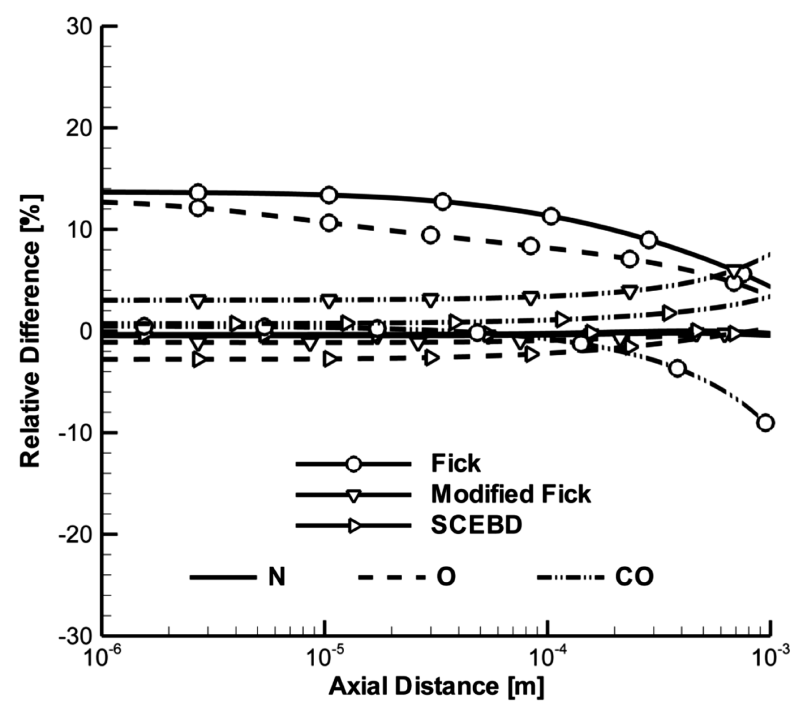

d) $51 \mathrm{~km}$

Fig. 15 Difference in N, O, and CO mole fractions along the stagnation line calculated using the Fick's model, modified Fick's model, and SCEBD model relative to Stefan-Maxwell model.

\section{Conclusions}

The goal of this study was to evaluate the effects of models commonly used to calculate the transport properties of multicomponent mixtures in CFD simulations on the flowfield predictions of reentry vehicles employing ablative heat shields. The Stardust sample return capsule was used as the test case with freestream conditions corresponding to four different trajectory points $(71,62$, 54 , and $51 \mathrm{~km}$ ). The numerical simulations were performed using the LeMANS CFD code. Surface reactions were included using the mechanisms developed by Driver et al. [27,28] for PICA and FiberForm, which include carbon oxidation and nitrogen catalysis.

In the first part of the study, the effects of the mixture transport coefficient models were assessed using two different models while holding constant the model for species mass diffusion fluxes (modified Fick's model). The first model is Wilke's mixing rule, with Blottner's curve fits and Eucken's relation used to determine the viscosity and thermal conductivities of individual species, respectively. The second model is Gupta's mixing rule with species viscosities and thermal conductivities calculated using collision cross-section data. The results showed that the heat transfer predicted using the Wilke/Blottner/Eucken model is in good agreement with the Gupta/CCS solution when the flowfield temperatures are relatively low. In the context of the Stardust entry conditions, this corresponds to trajectory altitudes below approximately $51 \mathrm{~km}$. For higher altitudes, the heat transfer predicted using the Wilke/ Blottner/Eucken model was shown to be larger than the value obtained with the Gupta/CCS model by approximately $15 \%$ for the $54 \mathrm{~km}$ conditions and $60 \%$ for the $71 \mathrm{~km}$ conditions. The mass blowing rate due to the oxidation of bulk carbon was also between $15 \%(51 \mathrm{~km})$ and $25 \%(62 \mathrm{~km})$ larger for the Wilke/Blottner/Eucken model than for the Gupta/CCS model.

The second part of the study focused on assessing the models for mass diffusion using the Fick's, modified Fick's, SCEBD, and Stefan-Maxwell models while holding constant the model for mixture transport coefficients (Gupta/CCS model). The results showed that the flowfield properties calculated using the modified Fick's, SCEBD, and Stefan-Maxwell models were in good agreement for all of the trajectory conditions considered in this study. However, the Fick's model produced a larger heat transfer and mass blowing rate for all of the trajectory conditions considered in this study relative to the other models. The source of the problem is that the Fick's model does not enforce the requirement that the diffusion mass fluxes sum to zero. Therefore, CFD simulations of ablative heat shields should avoid the Fick's model and use either the modified Fick's model or the SCEBD model, which can efficiently replicate the flowfield solutions obtained using the Stefan-Maxwell model. 
These results highlight the significant effects of the transport properties on the predicted aerothermal environment of reentry capsules that employ ablative TPS.

\section{Acknowledgments}

The authors gratefully acknowledge funding for this work through NASA Small Business Innovation Research Phase II contract NNX11CA27C. The authors thank Matthew MacLean (CUBRC, Inc.) for sharing the finite-rate surface chemistry module used in this work. The use of supercomputers through the NASA Advanced Supercomputing Division is essential to this work and is also greatly appreciated.

\section{References}

[1] Sutton, K., and Gnoffo, P. A., "Multi-Component Diffusion with Application to Computational Aerothermodynamics," AIAA Paper 1998-2575, June 1998.

[2] Gosse, R., and Candler, G., "Diffusion Flux Modeling: Application to Direct Entry Problems," AIAA Paper 2005-0389, Jan. 2005.

[3] Chen, Y., and Milos, F. S., "Finite-Rate Ablation Boundary Conditions for a Carbon-Phenolic Heat-Shield," AIAA Paper 2004-2270, June 2004.

[4] Palmer, G. E., and Wright, M. J., "Comparison of Methods to Compute High-Temperature Gas Viscosity," Journal of Thermophysics and Heat Transfer, Vol. 17, No. 2, 2003, pp. 232-239. doi: $10.2514 / 2.6756$

[5] Magin, T. E., and Degrez, G., "Transport Algorithms for Partially Ionized and Unmagnetized Plasmas," Journal of Computational Physics, Vol. 198, No. 2, 2004, pp. 424-449. doi:10.1016/j.jcp.2004.01.012

[6] Scalabrin, L. C., "Numerical Simulation of Weakly Ionized Hypersonic Flow over Reentry Capsules," Ph.D. Thesis, Univ. of Michigan, Ann Arbor, MI, 2007.

[7] Martin, A., Scalabrin, L. C., and Boyd, I. D., "High Performance Modeling of Atmospheric Re-Entry Vehicles," Journal of Physics: Conference Series, Vol. 341, No. 1, 2012, Paper 012002. doi:10.1088/1742-6596/341/1/012002

[8] MacCormack, R. W., and Candler, G. V., "The Solution of the NavierStokes Equations Using Gauss-Seidel Line Relaxation," Computers and Fluids, Vol. 17, No. 1, 1989, pp. 135-150. doi:10.1016/0045-7930(89)90012-1

[9] Marschall, J., and MacLean, M., "Finite-Rate Surface Chemistry Model, I: Formulation and Reaction System Examples," AIAA Paper 2011-3783, June 2011.

[10] MacLean, M., Marschall, J., and Driver, D. M., "Finite-Rate Surface Chemistry Model, II: Coupling to Viscous Navier-Stokes Code," AIAA Paper 2011-3784, June 2011.

[11] Alkandry, H., Farbar, E. D., and Boyd, I. D., "Evaluation of Finite-Rate Surface Chemistry Models for Simulation of the Stardust Reentry Capsule," AIAA Paper 2012-2874, June 2012.

[12] Karypis, G., and Kumar, V., "METIS: A Software Package for Partitioning Unstructured Graphs, Partitioning Meshes, and Computing Fill-Reducing Orderings of Sparse Matrices," Univ. of Minnesota, Minneapolis, MN, 1998.
[13] Wilke, C. R., "A Viscosity Equation for Gas Mixtures," Journal of Chemical Physics, Vol. 18, No. 4, 1950, pp. 517-519. doi:10.1063/1.1747673

[14] Blottner, F. G., Johnson, M., and Ellis, M., "Chemically Reacting Viscous Flow Program for Multi-Component Gas Mixtures," Sandia Labs TR-SC-RR-70-754, Albuquerque, NM, 1971.

[15] Vincenti, W. G., and Kruger, C. H., Introduction to Physical Gas Dynamics, Krieger, Malabar, FL, 2002, p. 21.

[16] Gupta, R. N., Yos, J. M., Thompson, R. A., and Lee, K.-P., "A Review of Reaction Rates and Thermodynamic and Transport Properties for an 11-Species Air Model for Chemical and Thermal Nonequilibrium Calculations to 30000 K," NASA Rept. Nasa-rp-1232, 1990.

[17] Wright, M. J., Bose, D., Palmer, G. E., and Levin, E., "Recommended Collision Integrals for Transport Property Computations, Part 1: Air Species," AIAA Journal, Vol. 43, No. 12, 2005, pp. 2558-2564. doi:10.2514/1.16713

[18] Wright, M. J., Hwang, H. H., and Schwenke, D. W., "Recommended Collision Integrals for Transport Property Computations, Part 2: Mars and Venus Entries," AIAA Journal, Vol. 45, No. 1, 2007, pp. 281-288. doi: $10.2514 / 1.24523$

[19] Kuo, K. K., Principles of Combustion, Wiley, New York, 2005, p. 289.

[20] Ramshaw, J. D., and Chang, C. H., "Friction-Weighted Self-Consistent Effective Binary Diffusion Approximation," Journal of Non-Equilibrium Thermodynamics, Vol. 21, No. 3, Jan. 1996, pp. 223-232. doi:10.1515/jnet.1996.21.3.223

[21] Ramshaw, J. D., and Chang, C. H., "Ambipolar Diffusion in TwoTemperature Multicomponent Plasmas," Plasma Chemistry and Plasma Processing, Vol. 13, No. 3, 1993, pp. 489-498. doi:10.1007/BF01465878

[22] Tran, H. K., Johnson, C. E., Rasky, D. J., Hui, F. C. L., Hsu, M.-T., and Chen, Y. K., "Phenolic Impregnated Carbon Ablators (PICA) for Discovery Class Missions,” AIAA Paper 1996-1911, June 1996.

[23] Olynick, D., Chen, Y.-K., and Tauber, M. E., "Aerothermodynamics of the Stardust Sample Return Capsule," Journal of Spacecraft and Rockets, Vol. 36, No. 3, 1999, pp. 442-462. doi: $10.2514 / 2.3466$

[24] Martin, A., Boyd, I. D., Cozmuta, I., and Wright, M. J., "Chemistry Model for Ablating Carbon-Phenolic Material During Atmospheric ReEntry," AIAA Paper 2010-1175, Jan. 2010.

[25] Martin, A., and Boyd, I. D., "CFD Implementation of a Novel CarbonPhenolic-in-Air Chemistry Model for Atmospheric Re-Entry," AIAA Paper 2011-0143, Jan. 2011.

[26] Martin, A., and Boyd, I. D., "Modeling of Heat Transfer Attenuation by Ablative Gases During the Stardust Re-Entry," AIAA Paper 2012-0814, Jan 2012. doi:10.2514/6.2012-814

[27] Driver, D. M., Olsen, M. W., Barnhardt, M. D., and MacLean, M., "Understanding High Recession Rates of Carbon Ablators Seen in Shear Tests in an Arc Jet," AIAA Paper 2010-1177, Jan. 2010.

[28] Driver, D. M., and MacLean, M., "Improved Predictions of PICA Recession in Arc Jet Shear Tests," AIAA Paper 2011-0141, Jan. 2011.

[29] Stackpoole, M., Sepka, S., Cozmuta, I., and Kontinos, D., "Post-Flight Evaluation of Stardust Sample Return Capsule Forebody Heatshield Material," AIAA Paper 2008-1202, Jan. 2008.

[30] Desai, P. N., and Qualls, G. D., "Stardust Entry Reconstruction," Journal of Spacecraft and Rockets, Vol. 47, No. 5, 2010, pp. 736-740. doi: $\underline{10.2514 / 1.37679}$ 